Article

\title{
Seismic Vulnerability Assessment of Hybrid Mold Transformer Based on Dynamic Analyses
}

\author{
Ngoc Hieu Dinh, Joo-Young Kim, Seung-Jae Lee and Kyoung-Kyu Choi * \\ School of Architecture, Soongsil University, 369 Sangdo-ro, Dongjak-gu, Seoul 06978, Korea \\ * Correspondence: kkchoi@ssu.ac.kr or kkchoi97@gmail.com; Tel.: +82-2-820-0998
}

Received: 2 July 2019; Accepted: 2 August 2019; Published: 5 August 2019

\begin{abstract}
In the present study, the seismic vulnerability of a hybrid mold transformer was investigated using a dynamic analytical approach incorporating the experimental results of shaking table tests. The analytical model consisted of linear springs and plastic beam elements, and it has six degrees of freedom simulating the hybrid mold transformer. The dynamic characteristics of the analytical model were determined based on the shaking table tests. The reliability of the analytical model was verified by comparing the test results and analytical results. In order to assess the seismic vulnerability, three critical damage states observed during the shaking table tests were investigated by incorporating the three performance levels specified in ASCE 41-17. Comprehensive dynamic analyses were performed with a set of twenty earthquakes in consideration of the variation of the uncertain parameters (such as the effective stiffness and coil mass) of the mold transformer. Based on the analytical results, fragility curves were established to predict the specified exceedance probability of the mold transformer according to the performance levels.
\end{abstract}

Keywords: hybrid mold transformer; probability of exceedance; analytical model; nonstructural elements; fragility curve; seismic vulnerability assessment

\section{Introduction}

Over the last few decades, strong earthquake ground motions have caused severe physical and functional damage not only to structural systems, but also to nonstructural elements, which have in turn led to major operational failures and economic losses in radical buildings, and special facilities such as hospitals, high-tech laboratories, power stations, and nuclear power plants. Among the various types of nonstructural elements, critical functional components such as electrical systems have been shown to cause major economic losses inside buildings during earthquakes [1-4]. Previous earthquake events including the 1994 Northridge earthquake in Los Angeles, the 2008 Great Sichuan Sichuan earthquake in China, the 2010 Maule earthquake in Chile, and the 2010 Sierra El Mayor earthquake in Mexico have shown that $25,230 \mathrm{kV}$ transformers are particularly vulnerable to earthquake damage in major buildings [5]. Recently, in South Korea, the 2016 Gyeongju and 2017 Pohang earthquakes caused significant deterioration to nonstructural electrical elements inside critical public buildings such as hospitals, Korea train express (KTX) railway stations, high schools, broadcasting stations, and shopping malls [6]. Therefore, seismic vulnerability assessment and safety evaluation of electrical elements have come to be recognized as key topics in the framework of earthquake risk mitigation.

In order to investigate the behavior and vulnerability of structural and nonstructural elements under realistic earthquakes, experimental earthquake simulation methods such as shaking table tests have been used by several previous research studies [7-15]. These shaking table tests could enable more realistic simulation and performance assessment of nonstructural elements. Nevertheless, the empirical data obtained from the test results can only be applied to limited regions for which the correlation between the dynamic response of nonstructural elements and characteristics of the earthquake is 
clearly tested. Thus, numerous shaking table tests using input ground motion that covers a large range of magnitudes as well as frequency content are necessary. Moreover, due to the variety in the specifications, configurations, support boundary conditions, and manufacturers of the nonstructural elements, in particular the electrical facilities in buildings, a limited number of shaking table tests could not provide sufficient information to assess the seismic vulnerability of the nonstructural elements. Accordingly, in order to comprehensively investigate the vulnerability of such nonstructural elements, reliable dynamic analyses could be used with intensive input earthquake ground motions.

To date, several studies have been conducted using analytical models to evaluate the seismic vulnerability of nonstructural elements, including mechanical and electrical facilities subjected to earthquake load. Zareei et al. [16] assessed the seismic vulnerability of a $400 \mathrm{kV}$ power transformer (PTR) by using 3D finite element modeling and time history analysis. In total, 99 tri-axial accelerograms of ground motions were considered as the input base excitations in the model of PTR. Seismic analytical fragility curves of PTR were obtained in two damage states using the Multiple Stripes Analysis approach to minimize the required number of structural analyses. The results indicated that this technique was efficient and that the analyses could be targeted at a limited number of important intensity measurement (IM) levels, as opposed to requiring analyses at all high or low IM levels. Hur [17] assessed the seismic response and vulnerability of switchboard cabinets mounted on building floors by using nonlinear numerical models. The main purpose of this study is to generate simplified numerical models of the switchboard cabinets using finite element (FE) methods to investigate the seismic behavior during earthquake events. Based on the numerical models, fragility curves were also constructed to evaluate the seismic vulnerability of the switchboard cabinets using comprehensive ground motions, and the seismic vulnerability obtained in this way was compared with the empirical data. In addition, a study by Wang et al. [18] presented an approach for estimating the seismic performance of large-scale Italian electric power system subjected to spatially correlated earthquake ground motions. The network flow theory was used to model the power flow allocation over the grid components, and the physical features and constraints of the power grid were considered. Accordingly, the overall vulnerability of the electric power system was evaluated, and the critical components of the grid system were identified. More recently, Vela et al. [19] investigated the seismic performance of an industrial frame-tank system using FE models. In this study, a braced frame supporting a cylindrical storage steel tank was selected and designed according to the AISC 360-10 code [20] and AISC 341-10 code [21]. The numerical model was then implemented by FE platform OpenSees (Open System for Earthquake Engineering Simulation) [22] and validated by using past experimental data collected by Nip et al. [23]. The storage tank analyses were performed in consideration of the connectivity with the supporting structures to determine the acceleration floor spectra and maximum response of the tank. Moreover, fragility models were derived to evaluate the vulnerability of the case study as well as the effectiveness of the analytical approaches. Nonetheless, the number of studies relevant to the seismic vulnerability assessment of nonstructural elements, particularly electrical elements in buildings, still remains rather limited.

In the present study, a simplified dynamic analytical model was proposed to assess the seismic vulnerability of a cast resin-type hybrid mold transformer. An analytical model simulating the hybrid mold transformer was composed of linear springs and plastic beam elements in consideration of the key features and dynamics characteristics of the transformer according to the shaking table test results. The effectiveness of the proposed model was validated with previous experimental data obtained from the shaking table tests with input acceleration time histories generated in accordance with the specifications recommended by the ICC-ES AC156 code [24]. Comprehensive time history dynamic analyses were performed with a variety of input earthquake ground motions considering the variation of the characteristics of the mold transformers including the effective stiffness and coil mass. Then, the fragility curves were derived to predict the exceedance probability of the hybrid mold transformer at specified performance levels corresponding to the damage states under earthquake load. 


\section{Description of a Hybrid Mold Transformer}

The hybrid mold transformer is an electrical element that has the advantages of a high-efficiency transformer as well as a power-saving function. Such transformers are power-saving devices that can help buildings save power by reducing unnecessary power loss. The hybrid mold transformer used in this study is the cast resin-type with a maximum capacity of $1000 \mathrm{kVA}$ and overall dimensions of $2110 \mathrm{~mm}$ (height) $\times 1900 \mathrm{~mm}$ (length) $\times 1030 \mathrm{~mm}$ (width). The total mass of the transformer was $3800 \mathrm{~kg}$ according to the data provided by the manufacturer. Figure 1 and Table 1 show brief descriptions of the major components of the transformer, which include the core, frame system (top beam, bottom beam, and bed beam), high-voltage (HV) coils, low-voltage (LV) coils, and various accessories (Lifting lugs, LV \& HV terminal, spacer, etc.). As shown in Figure 1, the core was made of cold rolled silicon steel and assembled with a frame system via bolt connections; the HV and LV coils cast in epoxy with a mold under vacuum were not strongly fixed to the core but instead indirectly connected through the friction generated from the compressive forces between the tightened bolts and spacers.

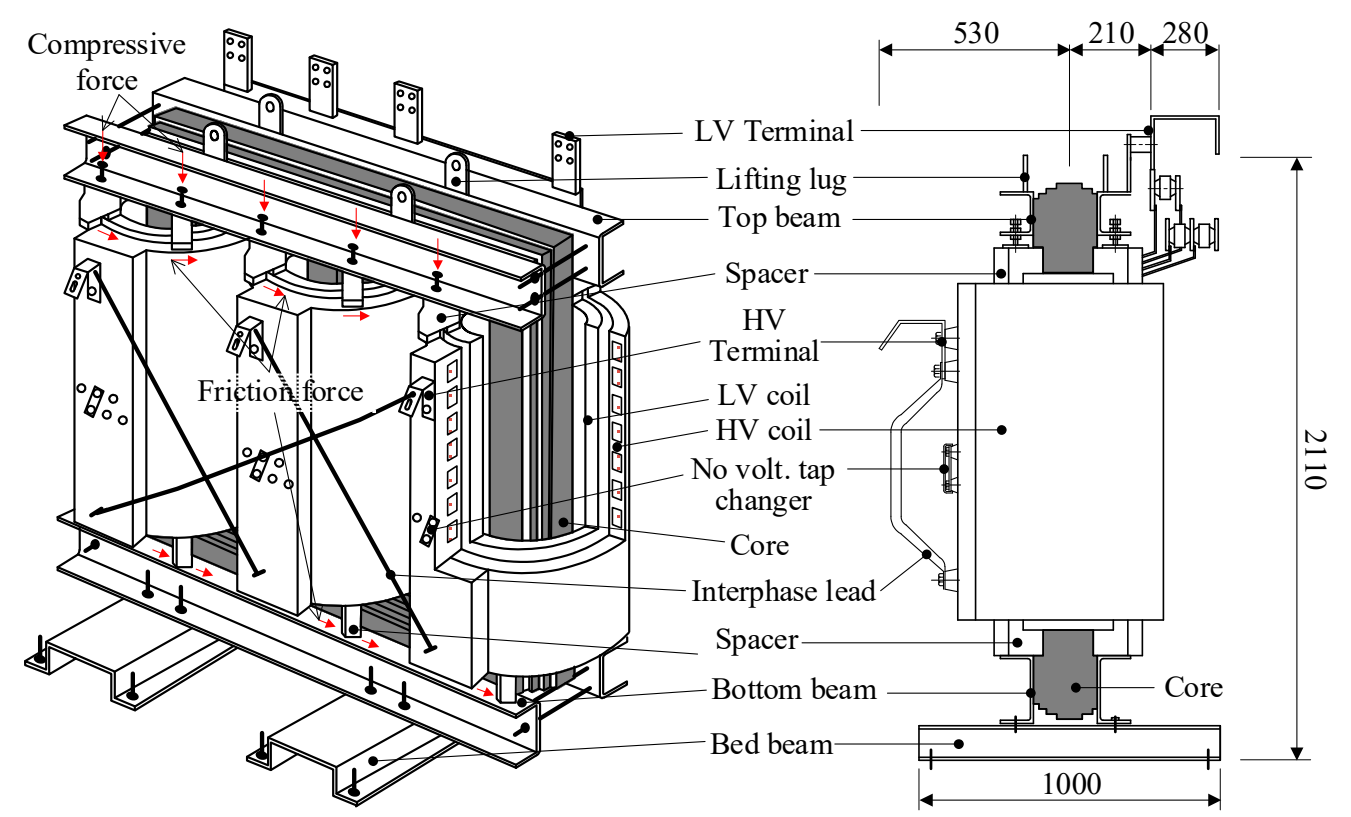

(a) Three-dimensional view

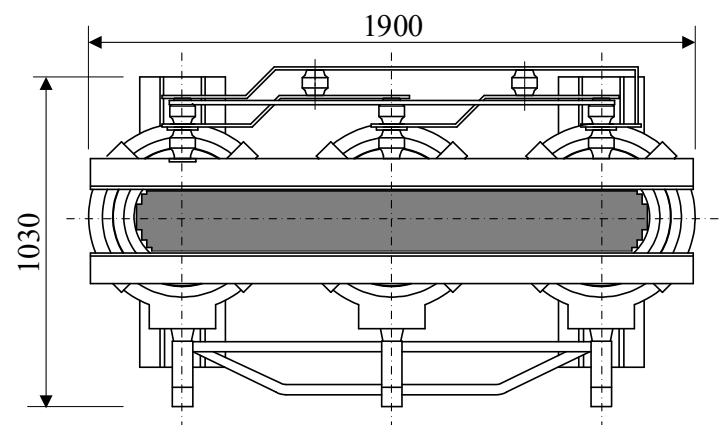

(c) Plan view (b) Side view

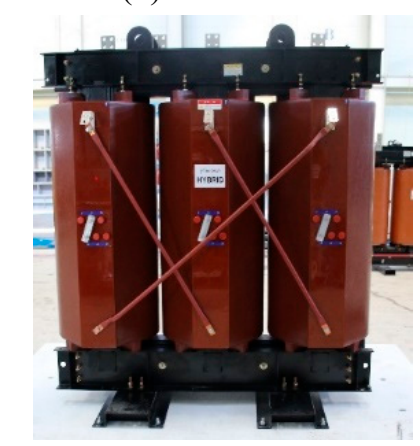

(d) Photo of hybrid mold transformer

Unit: $\mathrm{mm}$

Figure 1. Configurations and details of prototype hybrid mold transformer. 
Table 1. Detailed specifications of the prototype mold transformer.

\begin{tabular}{|c|c|c|c|c|c|c|c|c|}
\hline \multirow{2}{*}{$\begin{array}{c}\text { Power } \\
\text { Rating } \\
\text { (kVA) }\end{array}$} & \multirow{2}{*}{$\begin{array}{l}\text { Impedance } \\
( \pm 10 \%)\end{array}$} & \multirow{2}{*}{$\begin{array}{c}\text { Voltage } \\
\text { Regulation } \\
(\%)\end{array}$} & \multirow{2}{*}{$\begin{array}{c}\text { No-Load } \\
\text { Current } \\
(\%)\end{array}$} & \multirow{2}{*}{$\begin{array}{l}\text { Standard } \\
\text { Efficiency } \\
(\%)\end{array}$} & \multicolumn{3}{|c|}{ Dimensions } & \multirow{2}{*}{$\begin{array}{l}\text { Operating } \\
\text { Weight } \\
\text { (kg) }\end{array}$} \\
\hline & & & & & $\begin{array}{c}\text { Length } \\
\text { (mm) }\end{array}$ & $\begin{array}{l}\text { Width } \\
\text { (mm) }\end{array}$ & $\begin{array}{c}\text { Height } \\
\text { (mm) }\end{array}$ & \\
\hline 1000 & 4.99 & 1.3 & 2.5 & 99.4 & 1900 & 1030 & 2110 & 3800 \\
\hline
\end{tabular}

\section{Analytical Model Development of Hybrid Mold Transformer and its Validation}

\subsection{Analytical Model Development}

In this study, the analytical model was established by means of the MIDAS GEN commercial structural analysis program [25]. Figure 2 presents the analytical model of the mold transformer in detail. The analytical model was constructed to describe the major characteristics of the prototype specimen in terms of geometrical, mechanical, and dynamic properties. The configurations of the mold transformer (Figure 2a) can be divided into two major components of a frame system (Figure 2b) and coils (Figure 2c). The frame system consists of the top beams, bottom beams, bed beams, and steel core. Tables 2 and 3 report the mechanical properties of the mold transformer's components and the dynamic parameters of the mold transformer model, respectively. The steel core was modeled as beam elements using thin box-shaped cross-sections with dimensions of $240 \mathrm{~mm} \times 200 \mathrm{~mm}$. As shown in Figure 2e, in order to consider the mass distribution of the frame, the total steel core mass of 2.37 tons (according to the manufacturer's specifications) was divided into 11 distributed masses; the distributed masses at the centers of the vertical components (points B, E, and $\mathrm{H}$ ) are twice of those at the ends (points A, C, D, F, G, and K). In addition, as shown in Figure 2d, the bed and bottom beams were modeled as beam elements with U-shaped sections. The masses of the bed and bottom beams were evaluated considering the mass density of steel material $\left(7850 \mathrm{~kg} / \mathrm{m}^{3}\right)$ and the volumes of the beams, and those beams were connected together. The top beams were modeled in a similar manner to those of the bed and bottom beams. As shown in Figure $2 \mathrm{~d}$,e, the steel core model was connected to the bottom beam model at points $\mathrm{L}, \mathrm{M}$, and $\mathrm{N}$ via pairs of linear springs.

Based on the shaking table test results, the bolts connecting the bottom beams and bed beams were recognized as the main weak point of the prototype specimen. In the analytical model, such bolts were modeled as systems consisting of linear springs with stiffness $k_{i}$ and viscous dampers with the damping coefficient $c_{i}$, where $I=x-, y$-, and $z$-directions, as shown in Figure $2 \mathrm{~d}$. The stiffness $k_{\mathrm{i}}$ and damping $c_{i}$ were calculated based on the effective stiffness and damping ratio of the prototype specimen obtained from the shaking table test results (see Table 3). It is assumed that the damping behavior of the whole mold transformer was concentrated at the location of the bolts. The anchor bolts (M16) connecting the mold transformer and the concrete slab were modeled as linear springs with a fixed boundary condition by using the actual material stiffness of the M16 anchor bolts.

In addition, the coils were cast in epoxy with an average elastic modulus of $100,000 \mathrm{~N} / \mathrm{mm}^{2}$ and yield strength of $110 \mathrm{MPa}$, according to the specifications of the manufacturer. In the analytical model, three coils were modeled as the system of beam elements and connected to the core by the linear springs at points A-K, as shown in Figure $2 \mathrm{f}$. In order to consider the distribution of coil mass, the total mass of each coil of 0.42 ton (according to the manufacturer's specifications) was divided into 12 distributed masses at the top, middle, and bottom locations of each coil. The distributed masses at the middle are twice those at the top and bottom, as shown in Figure 2f. Each coil has a height and width of $1200 \mathrm{~mm}$ and $610 \mathrm{~mm}$, respectively. 


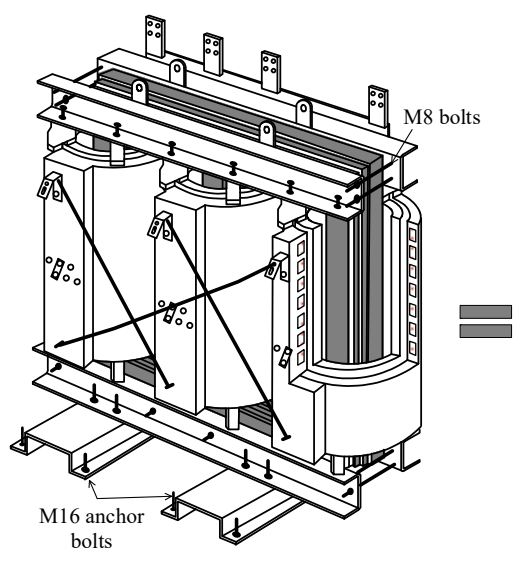

(a) Mold transformer

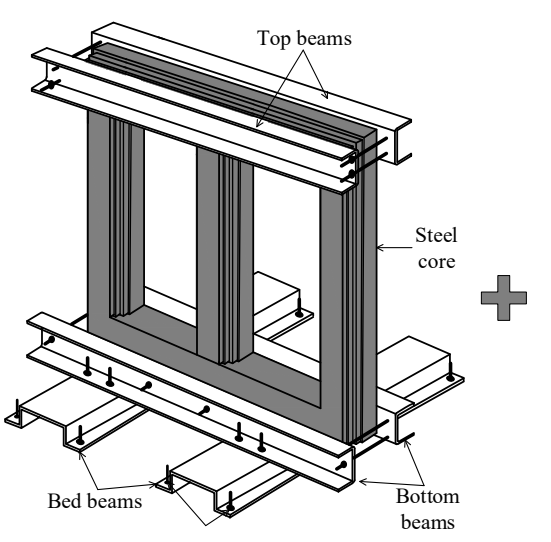

(b) Frame system

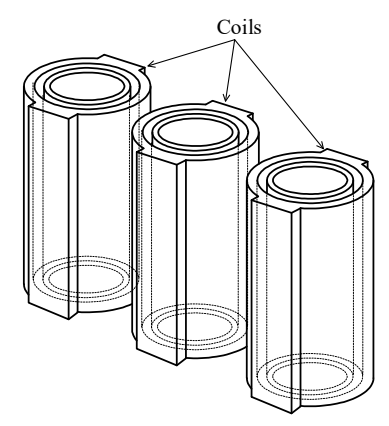

(c) Coils

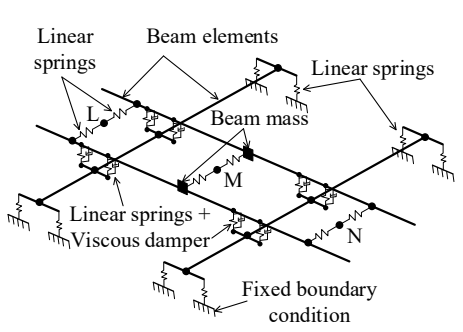

(d) Bed and bottom beam model

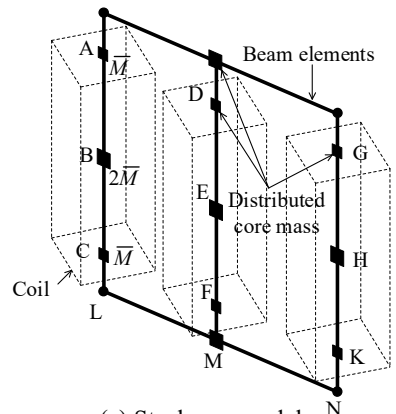

(e) Steel core model

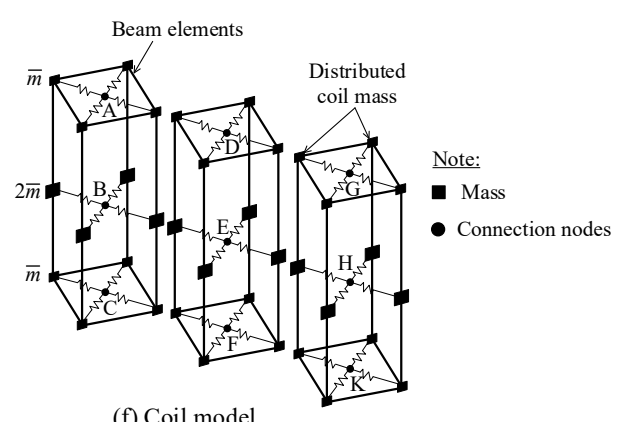

(f) Coil model

Figure 2. Details of components in analytical model.

Figure 3 shows the complete model of the mold transformer used in the MIDAS GEN program [25]. As shown in Figure 3, each node of the analytical model has six degrees of freedom (DOFs) and the whole model consists of a total of 462 DOFs. Elastic time history analyses were performed by using the Newmark average acceleration method [26] for direct integration to calculate the displacement, velocity, and acceleration response. The governing dynamic equation of the hybrid mold transformer subjected to a specific earthquake ground motion can be expressed as

$$
M \ddot{u}+C \dot{u}+K u=-M \ddot{u}_{g}
$$

where $M, K$, and $C$ represent the mass matrix, stiffness matrix, and damping matrix of the system, respectively; $u$ is the motion vector and $\ddot{u}_{g}$ is the ground motion acceleration vector.

The nodal velocity and displacement can be determined at the end of integration time step as

$$
\begin{gathered}
\dot{u}_{n+1}=\dot{u}_{n}+(1-\gamma) \Delta t \ddot{u}_{n+1} \\
u_{n+1}=u_{n}+\Delta t \dot{u}_{n}+\left(\frac{1}{2}-\beta\right) \Delta t^{2} \ddot{u}_{n}+\beta \Delta t^{2} \ddot{u}_{n+1}
\end{gathered}
$$

The nodal acceleration response in the time interval $t_{n}$ to $t_{n+1}$ can be calculated by the average acceleration method:

$$
\ddot{u}\left(t_{n}+\tau\right)=\frac{1}{2}\left(\ddot{u}_{n}+\ddot{u}_{n+1}\right)
$$

where $\gamma=1 / 2$ and $\beta=1 / 4$ are the parameters of the quadrature formula used in Newmark average acceleration method [26], and $\Delta t$ is the integration time step, which is determined small enough so that the average acceleration method is stable: 


$$
\frac{\Delta t}{T} \leq \frac{1}{2 \pi \sqrt{\gamma / 2-\beta}}
$$

In this study, for acceleration time history analysis, $\Delta t$ of $0.02 \mathrm{~s}$ was used as the integration time step in analytical program.

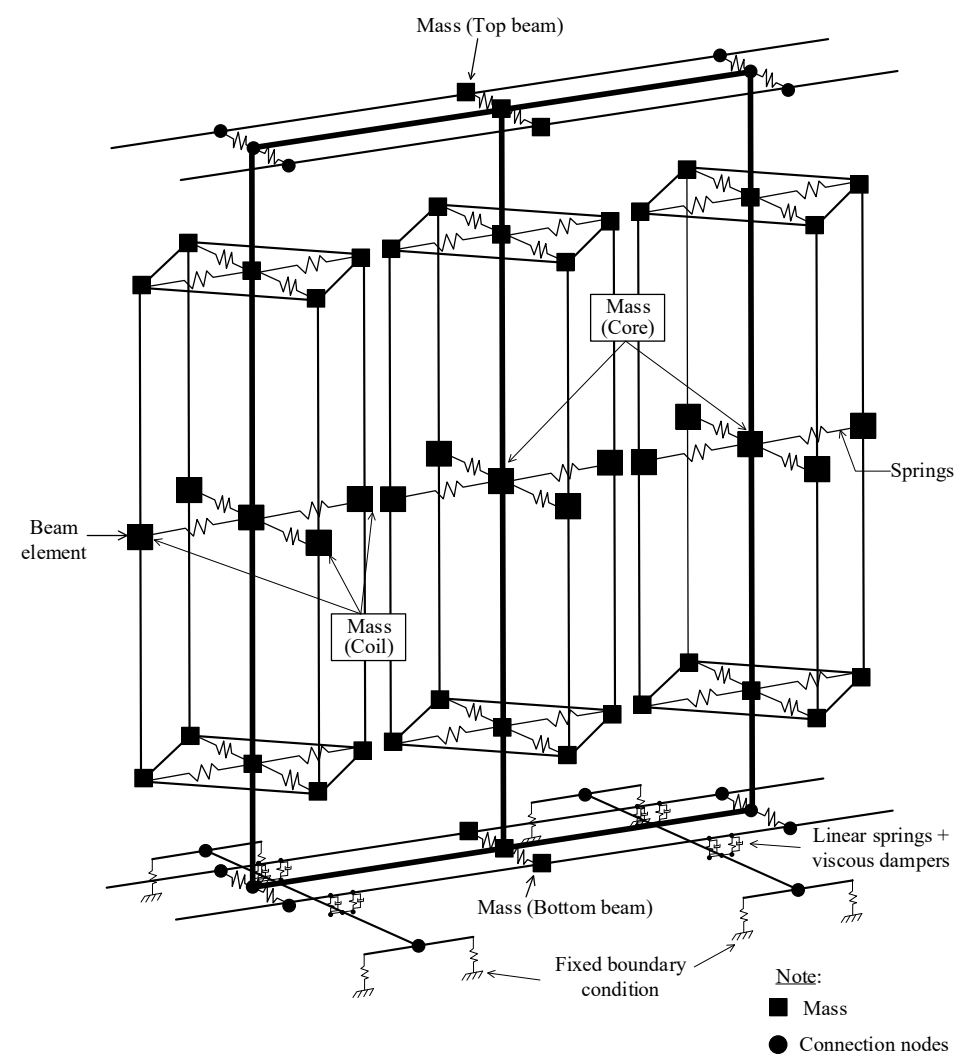

Figure 3. Complete analytical model used in analysis program.

Table 2. Mechanical parameters of the mold transformer.

\begin{tabular}{ccc}
\hline Components & Mechanical Parameters & Value \\
\hline Steel core & Elastic modulus $(\mathrm{MPa})$ & 200,000 \\
Top beams & Yield strength $(\mathrm{MPa})$ & 200 \\
Bottom beams & Weigh density $\left(\mathrm{kg} / \mathrm{m}^{3}\right)$ & 7850 \\
Bed beams & Elastic modulus $(\mathrm{MPa})$ & 100,000 \\
& Yield strength $(\mathrm{MPa})$ & 110 \\
Coils & Weigh density $\left(\mathrm{kg} / \mathrm{m}^{3}\right)$ & 1200 \\
\hline
\end{tabular}

Table 3. Dynamic parameters of the mold transformer.

\begin{tabular}{|c|c|c|c|}
\hline Parameters & & Value & \\
\hline Total frame mass ${ }^{(1)}$ (ton) & & 2.37 & \\
\hline Total coil mass ${ }^{(1)}$ (ton) & & 1.26 & \\
\hline Top beam mass (ton) & & 0.05 & \\
\hline Bottom beam mass (ton) & & 0.06 & \\
\hline Bed beam mass (ton) & & 0.07 & \\
\hline Damping ratio ${ }^{(2)}(\%)$ & & 4 & \\
\hline Effective stiffness ${ }^{(2)}(\mathrm{kN} / \mathrm{m})$ & 9080 (X-dir.) & 953 (Y-dir.) & 80,190 (Z-dir.) \\
\hline
\end{tabular}

(1) obtained from the manufacturer specifications. ${ }^{(2)}$ obtained from the shaking table test results. 


\subsection{Analytical Model Validation}

The accuracy of the aforementioned analytical modeling approach was assessed by comparing the analytical results to the experimental data from the shaking table tests [27]. In the shaking table test, the input acceleration-time histories were generated based on AC156 code for nonstructural elements [24]. Table 4 shows a brief summary of the peak ground acceleration (PGA) of each test label used in the shaking table test series. For model validation, test labels denoted as AC156_25, AC156_50, and AC156_100 were used and applied to the analytical model. Figure 4 shows the tri-axial acceleration time histories of AC156_25, AC156_50, and AC156_100.
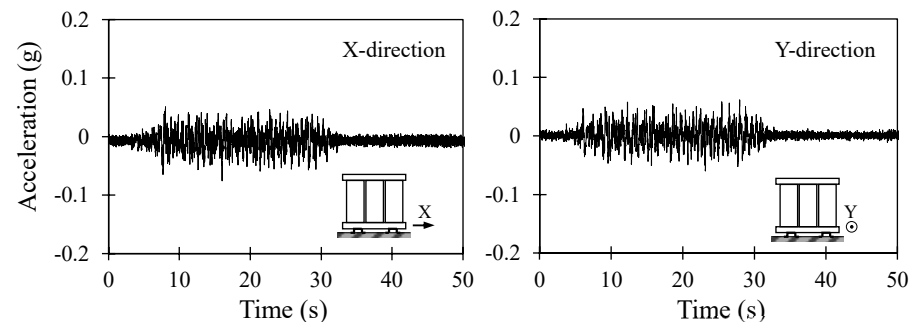

(a) AC156_25
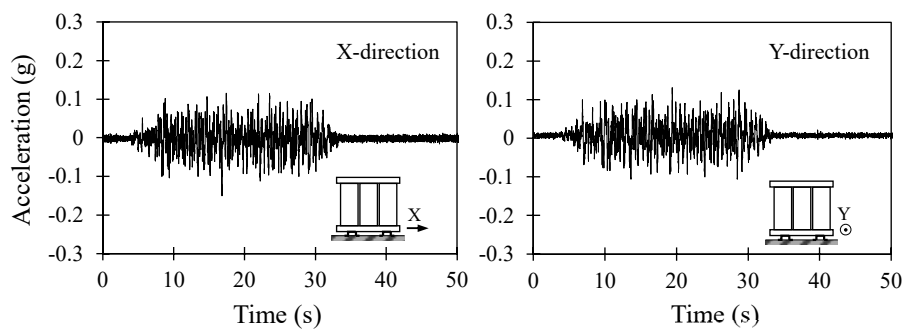

(b) AC156 50
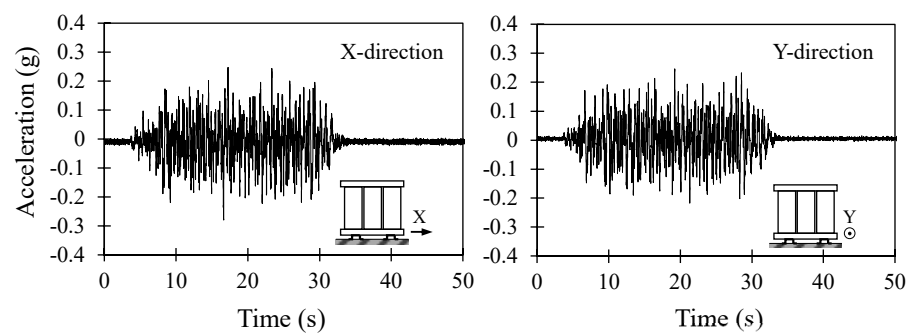

(c) AC156_100
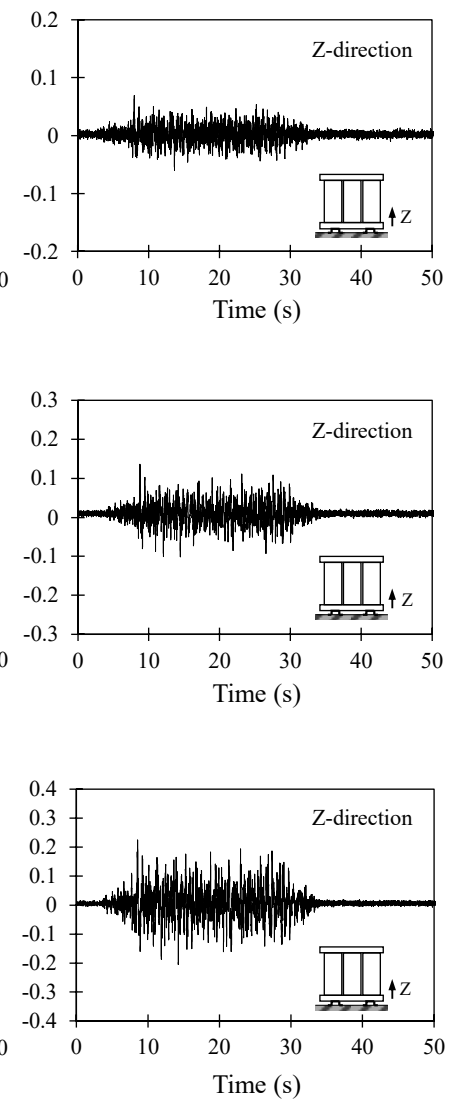

Time (s)

$$
\text { (n) }
$$

Figure 4. Input ground motion time histories used in dynamic analyses.

Table 4. Peak ground acceleration used in shaking table tests.

\begin{tabular}{cccc}
\hline \multirow{2}{*}{ Test Labels } & \multicolumn{3}{c}{ Input PGA $(\mathrm{g})$} \\
\cline { 2 - 4 } & X-dir & Y-dir & Z-dir \\
\hline AC156_25 & 0.08 & 0.07 & 0.07 \\
AC156_50 & 0.15 & 0.13 & 0.14 \\
AC156_75 & 0.21 & 0.17 & 0.18 \\
AC156_100 & 0.28 & 0.25 & 0.23 \\
AC156_125 & 0.33 & 0.30 & 0.27 \\
AC156_150 & 0.42 & 0.36 & 0.31 \\
AC156_175 & 0.50 & 0.43 & 0.39 \\
AC156_200 & 0.57 & 0.50 & 0.47 \\
AC156_250 & 0.70 & 0.64 & 0.58 \\
AC156_300 & 0.90 & 0.79 & 0.66 \\
\hline
\end{tabular}


Figures 5-7 compare the acceleration-time history responses obtained from the analytical and experiment results at the left coil subjected to the input acceleration time histories illustrated in Figure 4. The comparisons in Figures 5-7 indicated that the shapes of the acceleration-time history response and the peak amplitudes of acceleration response in the $X, Y$, and $Z$ directions obtained from the analytical results were consistent with the obtained test data. In addition, Figure 8 compares the Fourier-transform (FT) analyses results in the frequency domain of the response output signals acquired from the experimental and the analytical results. Despite the time differences, where the peak amplitude of the acceleration response occurred, the outcome of the FT analyses in the frequency domain was consistent with the experimental results in terms of the shape of amplitude-frequency curves and the frequency with respect to the peak amplitude.

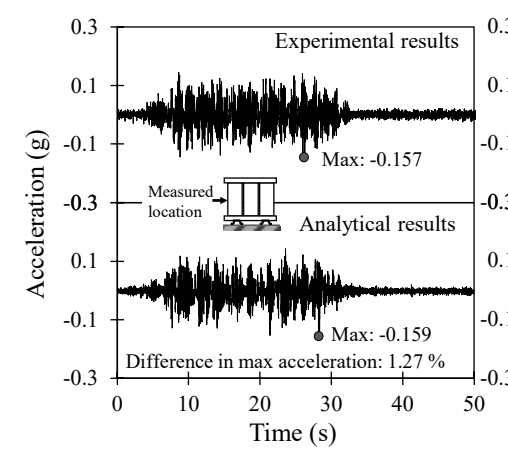

(a) X-direction

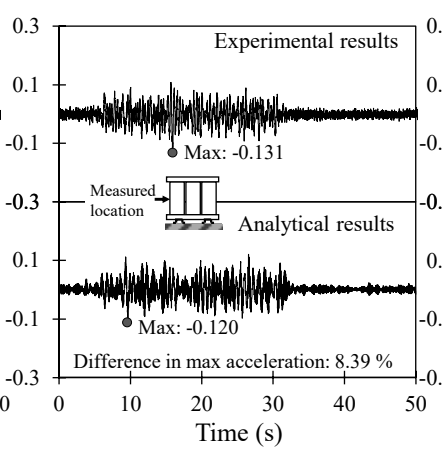

(b) Y-direction

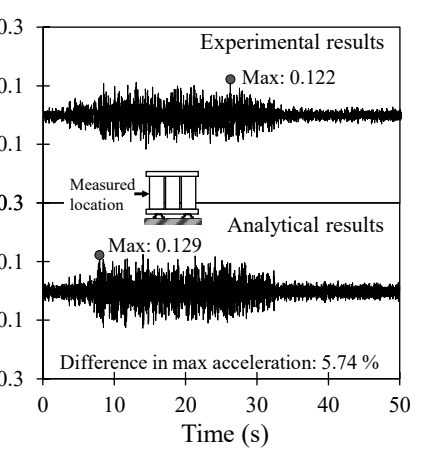

(c) Z-direction

Figure 5. Comparison of acceleration time history responses between analytical and experimental results for AC156_25.

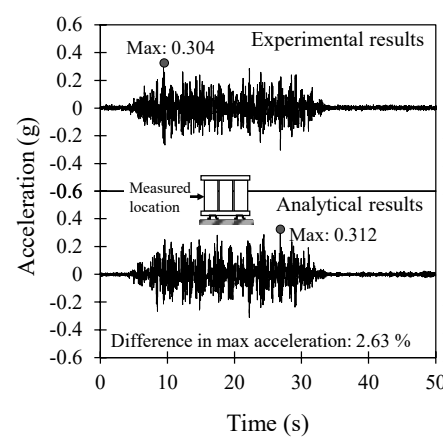

(a) X-direction

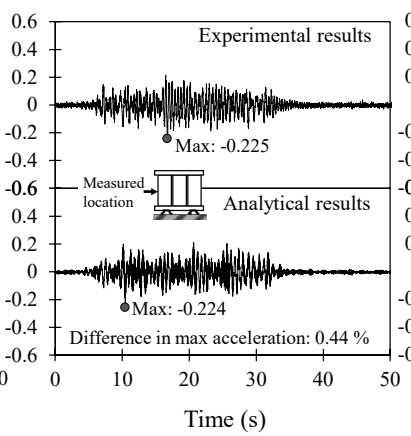

(b) Y-direction

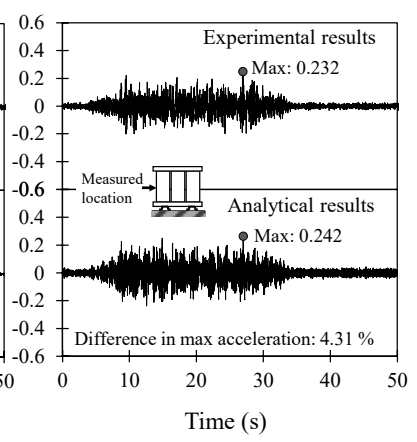

(c) Z-direction

Figure 6. Comparison of acceleration time history responses between analytical and experimental results for AC156_50.

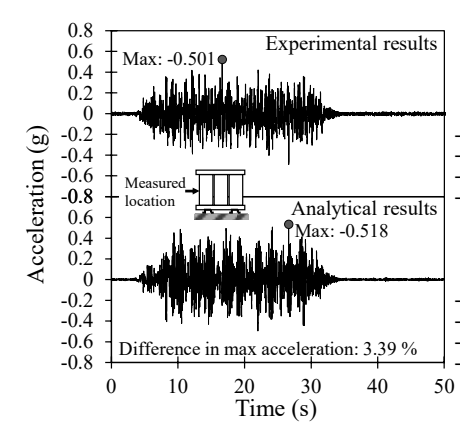

(a) X-direction

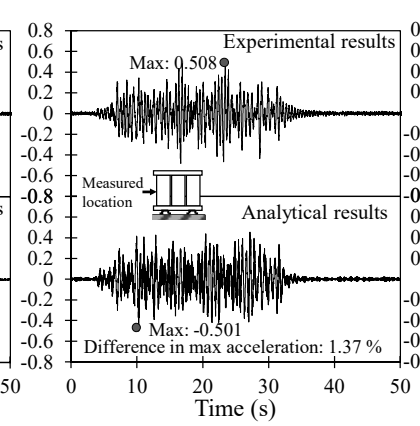

(b) Y-direction

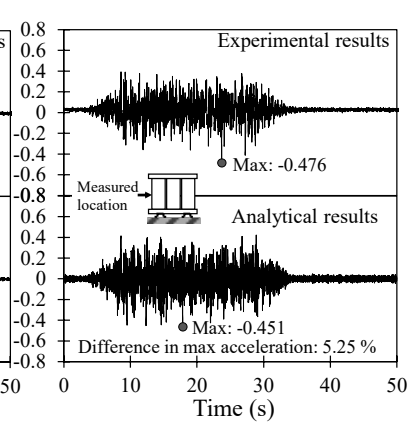

(c) Z-direction

Figure 7. Comparison of acceleration time history responses between analytical and experimental results for AC156_100. 

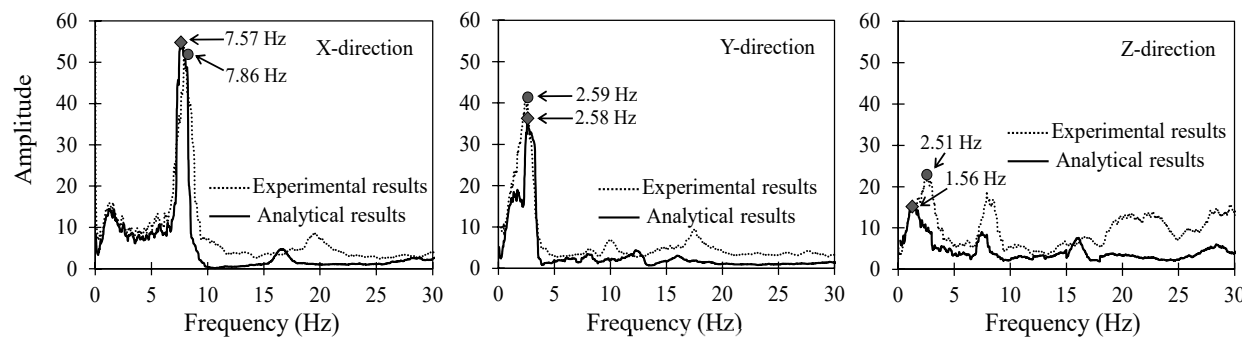

(a) AC156_25
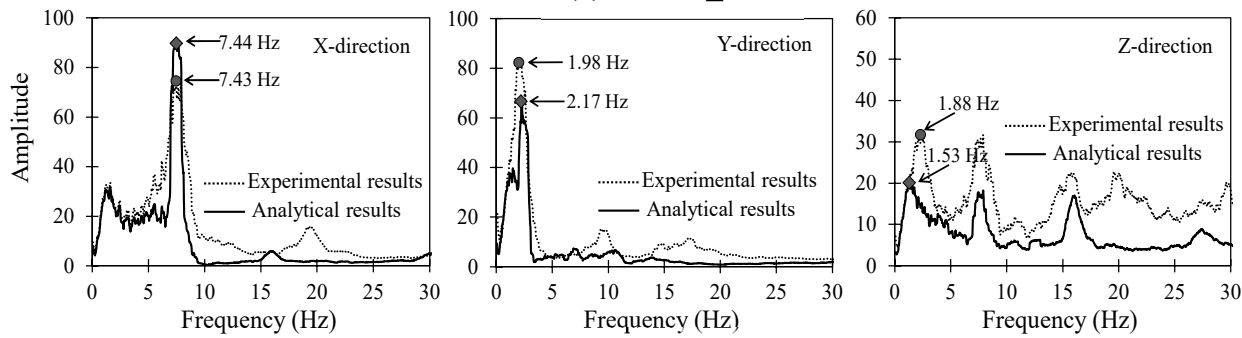

(b) AC156_50
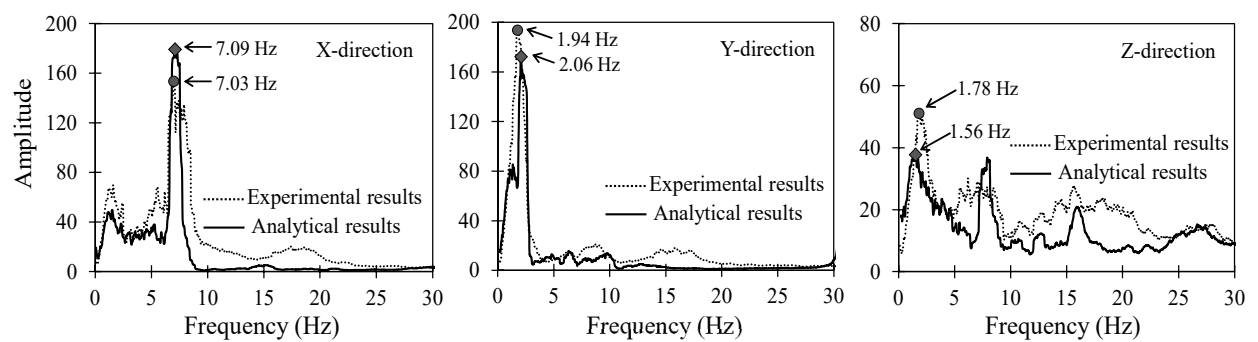

(c) $\mathrm{AC} 156100$

Figure 8. Comparison of analytical and experimental results after Fourier-transform (FT) analyses.

In addition, Figure 9 presents the results of the displacement-time history response in Y-direction of the mold transformers measured at the top beam subjected to AC156_100, AC156_200, and AC156_300, while Figure 10 shows a comparison between the analytical and experimental results in terms of the maximum displacement at the top beam of the mold transformer. Specifically, the figure showed good agreement between the analytical and experimental results in terms of the shape of response, the peak displacement, and the time corresponding to the peak displacement for a wide range of PGA. The differences in maximum displacement in Y-direction between experimental and analytical results were recorded of $6.59 \%, 5.41 \%$ and $4.68 \%$ in the cases of AC156_100, AC156_200, and AC156_300, respectively. This confirms that the analytical approach is reasonable and can be used to assess the seismic vulnerability of the mold transformer.
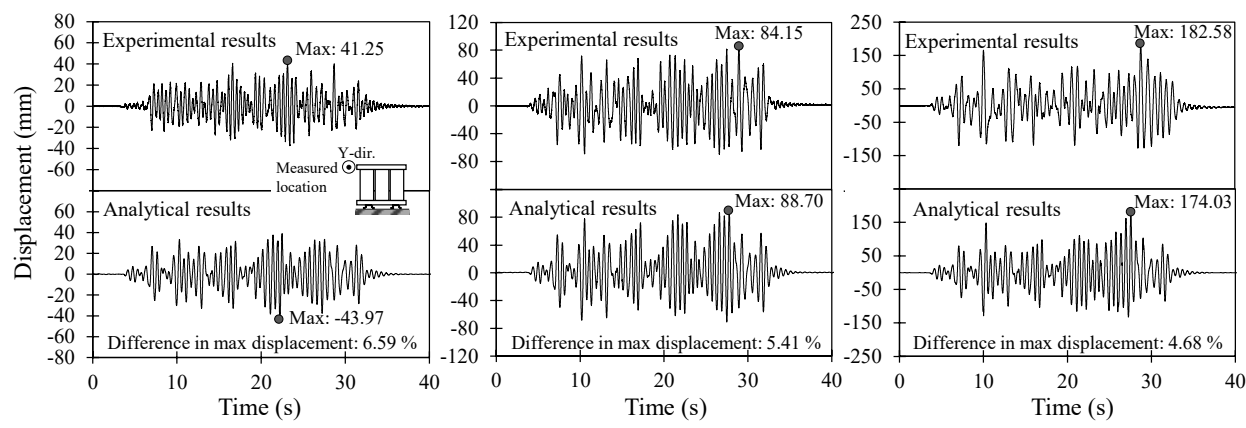

Figure 9. Comparison of displacement-time history responses in Y-direction between analytical and experimental results. 


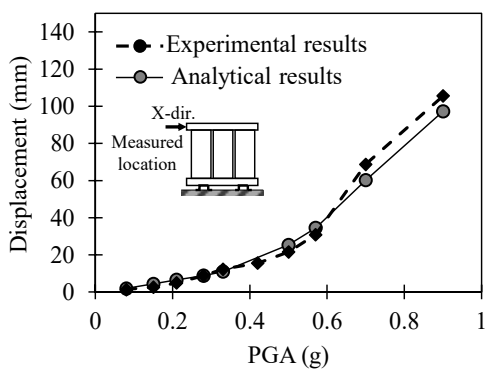

(a) X-direction

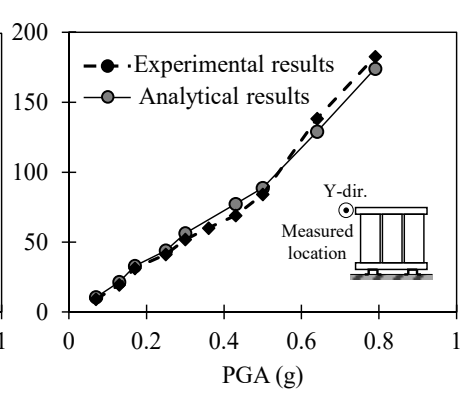

(b) Y-direction

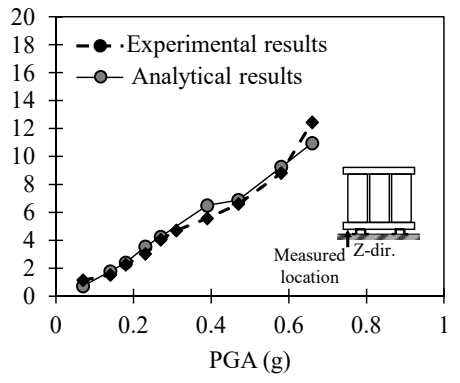

(c) Z-direction

Figure 10. Comparison of maximum displacement of the mold transformer between analytical and experimental results.

\section{Dynamic Analyses and Development of Seismic Fragility Curves}

\subsection{Methodology and Process for Developing Seismic Fragility Curves}

The seismic fragility curve is a mathematical function that illustrates the relation between a given intensity measure (IM) for a seismic event and the probability that the response of the component exceeds the limit state where the IM occurs. In the present study, the seismic fragility curves of the mold transformer component were established using truncated incremental dynamic analysis (TIDA) [28]. This approach involves a set of accelerograms scaled to certain levels of seismic intensities until the component collapses. Then, time history analyses were performed for each intensity level, and the maximum response of each component was recorded. The main advantage of this method is that it reduces the number of structural analyses and computational efforts. The uncertainties in the modeling components are considered by using a set of corresponding parameters after Zentner et al. [29]. Figure 11 shows a flowchart of the process of developing the seismic fragility curves for the mold transformer.

The fragility curves used for seismic vulnerable evaluation are natural logarithmic functions providing the probability of exceeding an identified response of a component for different intensity levels (IL) of the earthquake corresponding to a specified performance level. Accordingly, log-normal distribution is widely used to establish the fragility curves, not only for structural elements, according to the study of Cornell et al. [30], but also for nonstructural elements [16,17]. For a specified damage state (DS), the relation between the probability of exceedance and the specific IL values can be presented in terms of a log-normal distribution function as follows [28,31-33]

$$
P\left(D S \mid I L=x_{i}\right)=\Phi\left(\frac{\ln \left(x_{i} / \theta\right)}{\beta}\right)
$$

where $P$ is the probability for the cases that the component response will exceed a specified performance level at a given ground motion with $I L=x_{i}, \Phi$ is the standard normal cumulative distribution function, and $\theta$ and $\beta$ are the median and the standard deviation of the fragility function, respectively.

In order to fit the fragility curves from the observed analytical data, $\theta$ and $\beta$ could be evaluated by using the maximum likelihood estimator (LE) method for the entire data set [28,34] as follows

$$
L E=\prod_{i=1}^{m}\left(\frac{n_{i}}{z_{i}}\right) p_{i}^{z_{i}}\left(1-p_{i}\right)^{n_{i}-z_{i}}
$$

where $m$ is the number of PGA levels, $p_{i}$ is the probability that the component response will exceed a specified performance level at a given ground motion with $I L=x_{i}$ based on analytical results, $z_{i}$ is the number of exceedances out of $n_{i}$ ground motion, and $\Pi$ denotes a product over all PGA levels. Finally, parameters $\theta$ and $\beta$ were determined by maximizing the likelihood. 


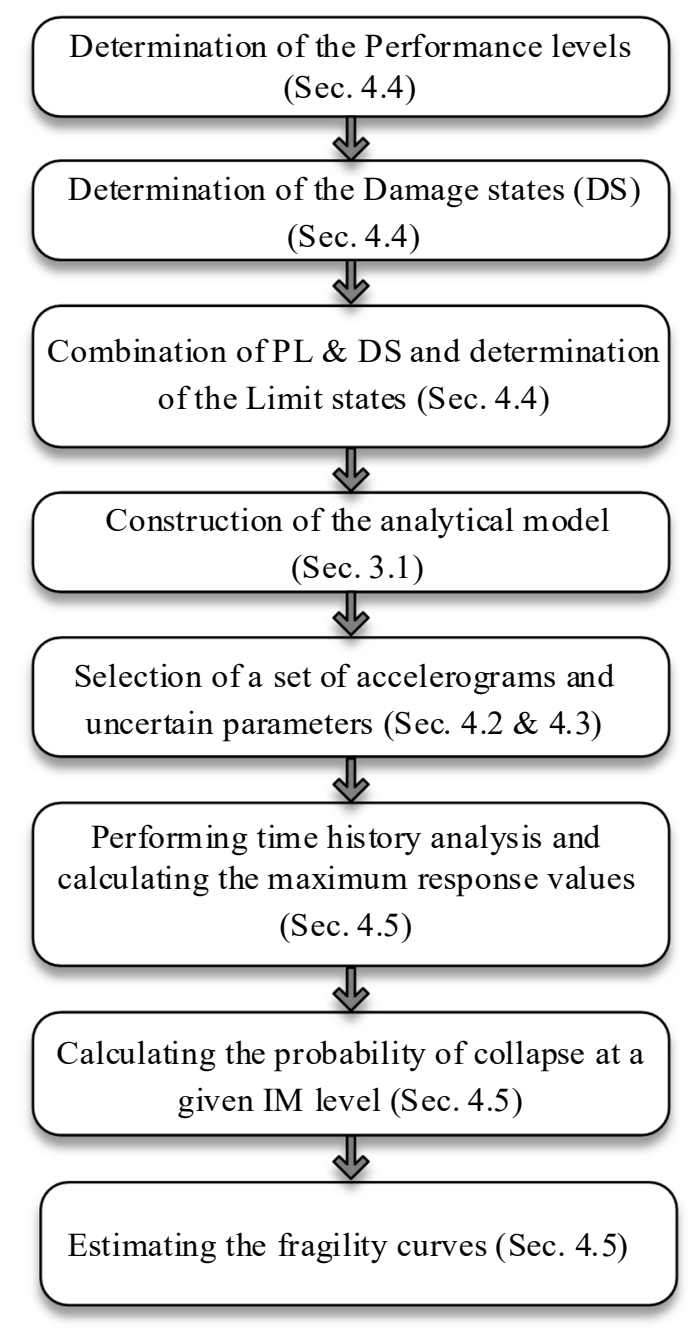

Figure 11. Flowchart of seismic vulnerability assessment process.

\subsection{Characteristics of Input Ground Acceleration Time Histories Used for Dynamic Analyses}

In order to assess the seismic vulnerability of the mold transformer using fragility curves, the selection of input ground motion for time history analyses is a key parameter. Vamvatsikos and Cornell [35] proposed the use of 10-20 input acceleration time histories when performing TIDA, while ATC-58 [36] recommended 20 time histories. Thus, in this study, 20 ordinary records of natural ground motion with both horizontal and vertical components were selected from the PEER database [37].

The time history ground motions were derived from historical recordings so that their mean response spectrum matched the target design acceleration spectrum evaluated according to the Korean Building Code (KBC 2016) [38]: $S_{d s}=0.497$ and $S_{d 1}=0.287$, and their shear wave velocity $\left(V_{s, 30}\right)$ in a range of $180 \mathrm{~m} / \mathrm{s}$ to $760 \mathrm{~m} / \mathrm{s}$, which was complied with the soil type C and D [38]. The SRSS-based pseudo-acceleration response spectrum of selected ground motion was demonstrated in Figure 12. The selected earthquake ground motions were presented in detail in Table 5. These earthquake records cover the ranges of magnitude from 5.5 to 7.5 , of shear wave velocity $\left(V_{s, 30}\right)$ from 198.77 to $634.33 \mathrm{~m} / \mathrm{sec}$, and of closet ruptured distance $\left(R_{\text {rup }}\right)$ from 4.06 to $199.84 \mathrm{~km}$. Scatter diagrams of magnitude versus closet ruptured distance $\left(R_{\text {rup }}\right)$ and magnitude versus peak ground acceleration of the selected ground motions are illustrated in Figures 13 and 14, respectively. 
Table 5. Details of the selected earthquake ground motion.

\begin{tabular}{lllllll}
\hline No & Earthquake Name & Station Name & Year & Magnitude & $\boldsymbol{R}_{\text {rup }}(\mathbf{k m})$ & $V_{s, \mathbf{3 0}}(\mathbf{m} / \mathbf{s e c})$ \\
\hline 1 & Humbolt Bay & Ferndale City Hall & 1937 & 5.8 & 71.57 & 219.31 \\
2 & Imperial Valley-02 & El Centro Array \#9 & 1940 & 6.95 & 6.09 & 213.44 \\
3 & Northern Calif-01 & Ferndale City Hall & 1941 & 6.4 & 44.68 & 219.31 \\
4 & Borrego & El Centro Array \#9 & 1942 & 6.5 & 56.88 & 213.44 \\
5 & Kern County & LA - Hollywood Stor FF & 1952 & 7.36 & 117.75 & 316.46 \\
6 & Southern Calif & San Luis Obispo" & 1952 & 6 & 73.41 & 493.5 \\
7 & Northern Calif-03 & Ferndale City Hall & 1954 & 6.5 & 27.02 & 219.31 \\
8 & Northern Calif-04 & Ferndale City Hall & 1960 & 5.7 & 57.21 & 219.31 \\
9 & Hollister-01 & Hollister City Hall & 1961 & 5.6 & 19.56 & 198.77 \\
10 & Hollister-02 & Hollister City Hall & 1961 & 5.5 & 18.08 & 198.77 \\
11 & Parkfield & Cholame-Shandon Array \#8 & 1966 & 6.19 & 12.9 & 256.82 \\
12 & Borrego Mtn & LB - Terminal Island & 1968 & 6.63 & 199.84 & 217.92 \\
13 & San Fernando & Fairmont Dam & 1971 & 6.61 & 30.19 & 634.33 \\
14 & Managua_Nicaragua-01 & Managua_ESSO & 1972 & 6.24 & 4.06 & 288.77 \\
15 & Friuli_Italy-01 & Feltre & 1976 & 6.5 & 102.15 & 356.39 \\
16 & Gazli_USSR & Karakyr & 1976 & 6.8 & 5.46 & 259.59 \\
17 & Friuli_Italy-02 & Forgaria Cornino & 1976 & 5.91 & 14.75 & 412.37 \\
18 & Tabas_Iran & Dayhook & 1978 & 7.35 & 13.94 & 471.53 \\
19 & Tabas_Iran & Kashmar & 1978 & 7.35 & 194.55 & 280.26 \\
20 & Tabas_Iran & Sedeh & 1978 & 7.35 & 151.16 & 354.37 \\
\hline
\end{tabular}

\subsection{Intensity Measure, Intensity Levels, and Uncertainty in Modeling Parameters Used for Dynamic Analyses}

In order to construct the fragility curves using the TIDA approach, a series of time history analyses have been performed for a set of acceleration records, which were scaled to varying and increasing levels of seismic intensity. The parameter that informs the scaling of the acceleration records is typically known as the intensity measure (IM), while the degree of seismic intensity is referred to as the intensity level (IL). A common IM that has been widely used in seismic fragility analysis, peak ground acceleration (PGA) [16,39-41], was chosen in the present study. In particular, various levels of PGA with a range of 0.05 to $2 \mathrm{~g}$ were used as IL. This range of PGA was considered to ensure that the mold transformer could exhibit different performance levels to exceed the limit states.

Moreover, in reality, the mold transformers can be manufactured with different configurations and specifications, which can lead to variations in performance when subjected to the same earthquake. In order to consider such uncertainty in the modeling parameters of the mold transformer when estimating the fragility curves, various dynamic parameters of the mold transformer were investigated in terms of the effective stiffness and the coil mass. Specifically, three cases of effective translational stiffness $\left(0.8 K_{t}, 1.0 K_{t}\right.$, and $\left.1.2 K_{t}\right)$, three cases of effective rotational stiffness $\left(0.8 K_{\theta}, 1.0 K_{\theta}\right.$, and $\left.1.2 K_{\theta}\right)$, and three cases of coil mass $\left(0.6 \mathrm{M}_{\mathrm{c}}, 1.0 \mathrm{M}_{\mathrm{c}}\right.$, and $\left.1.2 \mathrm{M}_{\mathrm{c}}\right)$ were investigated for each time history analysis; based on the test results, $1.0 K_{t}, 1.0 K_{\theta}$, and $1.0 \mathrm{M}_{\mathrm{c}}$ were the values of the modeling parameters chosen for the prototype analytical model.

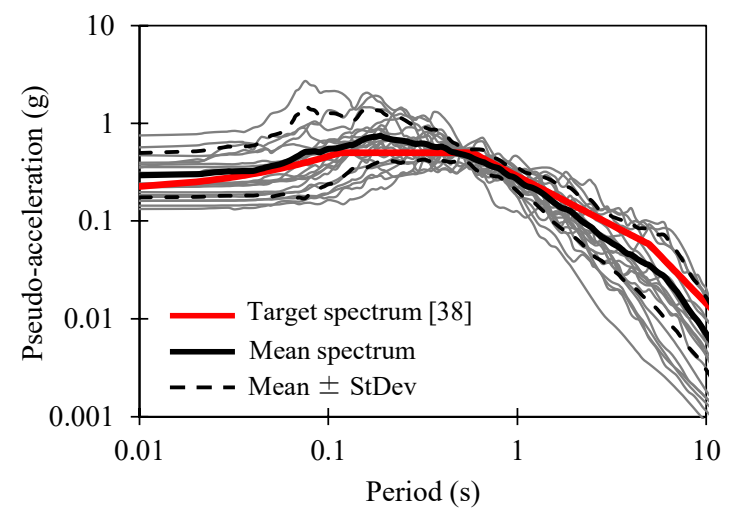

Figure 12. Response spectrum of selected ground motions. 


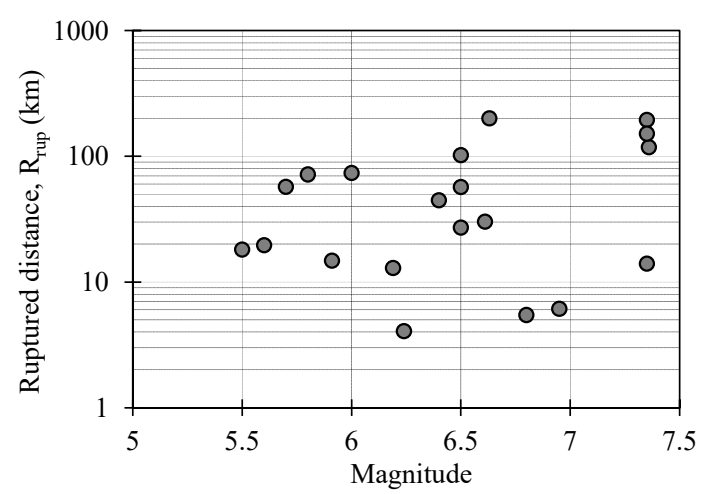

Figure 13. Magnitude versus closet ruptured distance of selected ground motions.

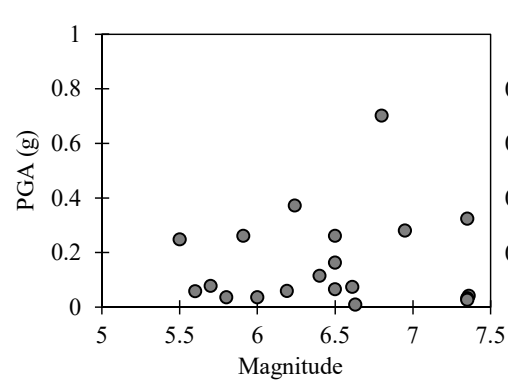

(a) X-direction

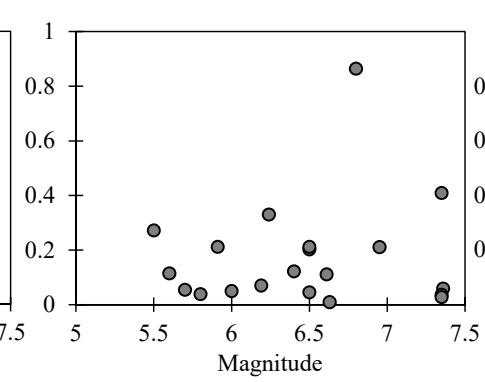

(b) Y-direction

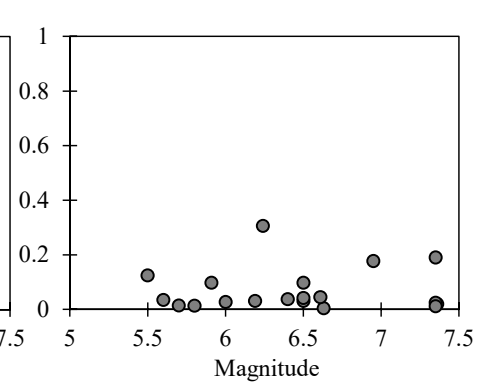

(c) Z-direction

Figure 14. Magnitude versus peak ground acceleration (PGA) of selected ground motions.

\subsection{Identifications of Damage States and Limit States}

From the shaking table test results, three weak points of the mold transformer were adopted as critical damage states, as shown in Figure 15. The first damage states (DS1) correspond to the failure of the spacers, the second damage states (DS2) correspond to the excessive coil movement in Y-direction, and the third damage states (DS3) correspond to the loosening of linked bolts between the bottom and bed beams. According to the recommendation specified in ASCE 41-17 Standard [42], the target performance levels used to evaluate the seismic vulnerability of the nonstructural elements for buildings can be selected among Operational (OP), Position Retention (PR), and Life Safety (LS). Specifically, the OP performance level involves the functional nonstructural equipment required for normal use regardless of minor damage; the PR performance level involves nonstructural equipment, which is secured in place and might be able to function if necessary service is available; and the LS performance level involves nonstructural equipment that can sustain significant damage but not become dislodged and fall in a manner that could cause death or serious injury to occupants or people. In order to evaluate the seismic performance of the mold transformer, the target performance levels were selected based on the correlation with critical damage states, as shown in Figure 16. Specifically, damage in spacers (DS1) can lead to slippage of the HV and LV coils away from the original positions and the interaction between them, which involve the OP and PR performance levels; and excessive movement in the Y-direction (DS2) can cause interaction with the adjacent equipment and breaking of the electrical wires, which involve the OP and PR performance levels; and the degree of loosening at the bottom bolts (DS3) can affect the functional operation or lead to the collapse of the entire transformer and threaten human life, which involve the OP, PR, and LS performance levels.

When correlating the performance levels and damage states, the values of the limit states were defined for each target performance level corresponding to the damage states. The parameters by which the limit states were evaluated were partly based on the observation from shaking table test results [27] and partly based on judgment. Specifically, for the DS1, the peak response acceleration at the coils (PRA) in the Y-direction is strongly related to the spacer damage due to the fact that the 
lowest effective stiffness is in this direction. Accordingly, for the DS1, the values of the limit states corresponding to the OP and PR performance levels were respectively determined to be $0.22 \mathrm{~g}$, which corresponds to the time when the cracks were initially formed, and $0.69 \mathrm{~g}$, which corresponds to the time when the spacers were failed, as observed during shaking table tests. For the DS2, the maximum displacement in the Y-direction at the top beams is strongly related to the excessive movement of the transformer. Accordingly, the values of the limit states corresponding to the OP and PR performance levels were determined to be $50 \mathrm{~mm}$ and $75 \mathrm{~mm}$, respectively, based on the provisions as well as the recommendations of the Korea Research Institute [43]. For the DS3, the maximum displacement in the Z-direction at the bottom beam is strongly related to the degree of loosening of the link bolted between the bottom beam and bed beam; and the values of the limit states corresponding to the OP, PR, and LS performance levels were determined to be $2.2 \mathrm{~mm}, 6.6 \mathrm{~mm}$, and $12.45 \mathrm{~mm}$, respectively, based on the experiment test results [27]. The summary of the value of the limit state corresponding to each damage state is presented in Table 6.

\subsection{Fragility Curves and Discussions}

The peak response results obtained from the analytical model of the mold transformer are illustrated in Figure 17 in terms of the different parameters represented for damage states: the peak response acceleration at the coils in the Y-direction (Figure 17a), maximum displacement at the top beam in the Y-direction (Figure 17b), and maximum displacement at the bottom beam in the Z-direction (Figure 17c). As the peak ground acceleration increases, the maximum response from the analytical model increases as well, indicating increased physical damage to the mold transformer. Moreover, the limit values corresponding to the damage states for each performance level are presented in Figure 17. In order to establish the fragility curves, these analytical results provide the fraction of the analyses that lead to the exceedance of limit states corresponding to specific performance levels. In total, 1120 cases were analyzed with consideration of the variety of earthquake ground motion characteristics and uncertainty in modeling parameters to establish the fragility curves of the hybrid mold transformers.

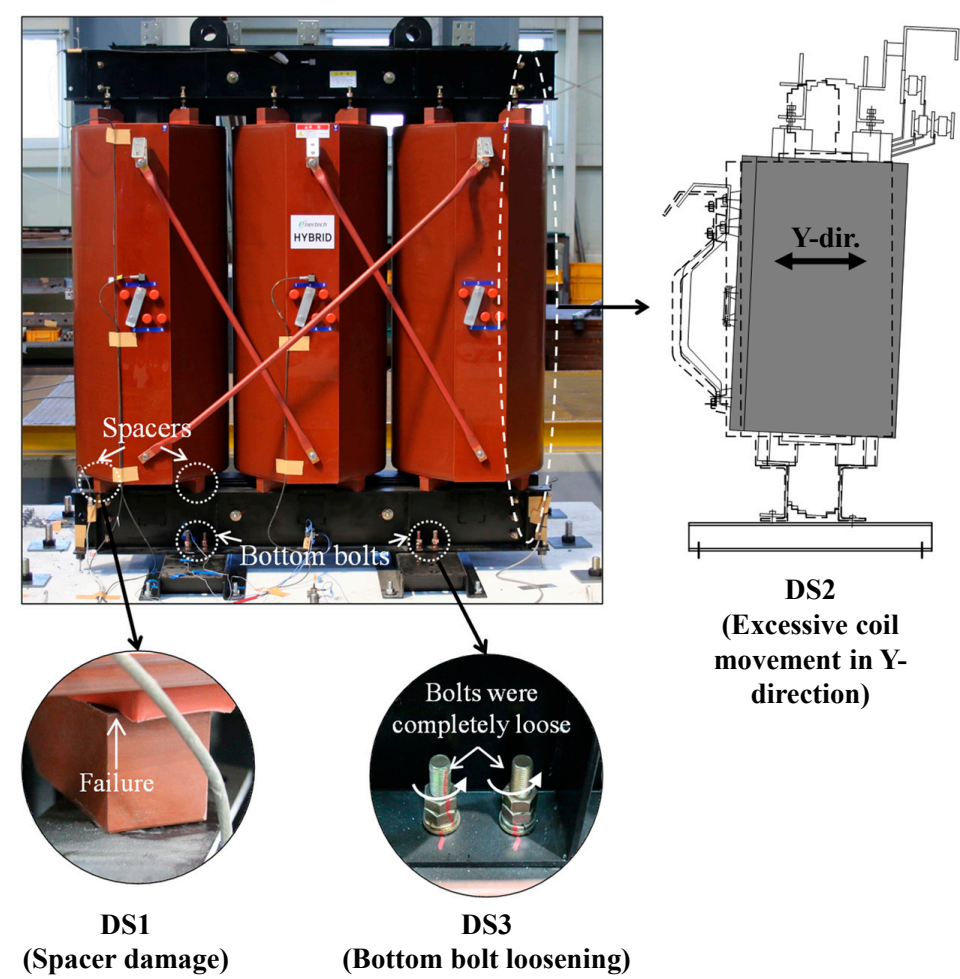

Figure 15. Critical damage states observed during the shaking table tests. 
Table 6. Values of limit states of the mold transformer.

\begin{tabular}{cccc}
\hline Damage States & Performance Levels & Parameter of Limit States & Value of Limit States \\
\hline \multirow{2}{*}{ DS1 } & OP & PRA of coils in Y-direction $(\mathrm{g})$ & 0.22 \\
& PR & Maximum displacement at the top & 0.69 \\
DS2 & OP & beam in Y-direction (mm) & 75 \\
& PR & Maximum displacement at the & 2.25 \\
OS3 & OP & bottom beam in Z-direction (mm) & 6.6 \\
& PR & 12.45 \\
\hline
\end{tabular}

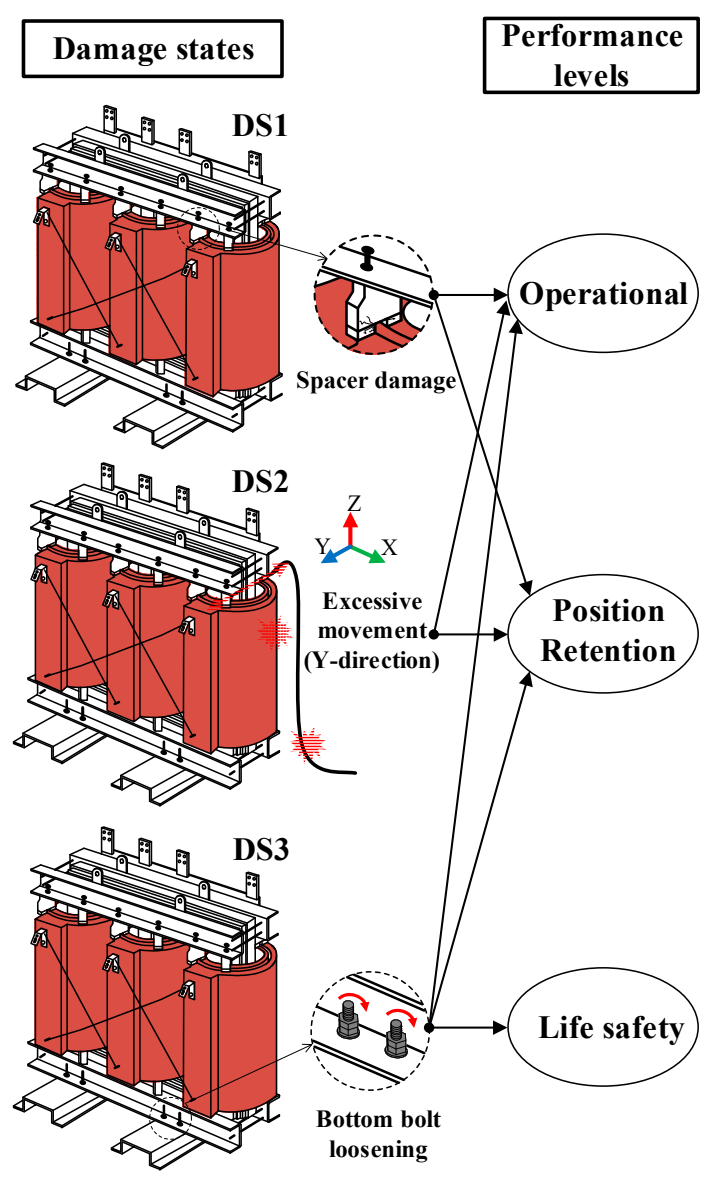

Figure 16. Correlation between damage states and performance levels of the mold transformer.

To further elucidate the effects of uncertain modeling parameters on the performance of the mold transformer in an earthquake, Figure 18 presents the characteristics of the Friuli_Italy-01 Earthquake used for dynamic analysis in terms of the acceleration time histories in the $\mathrm{Y}$ and Z-directions (Figure 18a,c) and corresponding FT results in the frequency domain (Figure 18b,d). In both directions, at least four resonance frequencies could be clearly observed in the frequency domain, from $1.67 \mathrm{~Hz}$ to $19.3 \mathrm{~Hz}$ in the $\mathrm{Y}$-direction. Figure 19 shows the effect of the mass coil, $\mathrm{M}_{\mathrm{c}}$, on the main responses of the transformer: peak response acceleration at the coil in the Y-direction, maximum displacement at the top beam in the Y-direction, and maximum displacement at the bottom beam in the Z-direction. In general, the peak response acceleration at the coil and the maximum displacement at the top beam in the Y-direction showed a nonlinear increase when the PGA was greater than $1.0 \mathrm{~g}$, while the maximum displacement at the bottom beam in the Z-direction showed a linear increasing trend. Moreover, when the coil mass varied in the range of 0.6 to $1.2 \mathrm{M}_{\mathrm{c}}$, at the PGA of $2.0 \mathrm{~g}$, the peak acceleration response in the Y-direction varied in the range of $17 \%$, the maximum displacement at the top beam in the Y-direction varied in the range of $15 \%$, and the maximum displacement at the bottom beam in the $Z$-direction varied in the range of $30 \%$. In Figure 20, the effect of the translational stiffness, $K_{t}$, on the 
main parameters was also presented. As shown in Figure 20a, the effective translational stiffness has a great influence on the peak acceleration response. For example, at the PGA of 2.0, the peak acceleration response in the Y-direction in the case of $1.0 K_{t}$ was about 50\% lower than that of $0.8 K_{t}$ and about 30\% greater than that of $1.2 K_{t}$. Meanwhile, the effective translational stiffness had a negligible influence on the displacement in the Y-direction and the Z-direction (Figure 20b,c). Moreover, in all cases, the effect of the rotational stiffness in the range of 0.8 to $1.2 K_{\theta}$ on parameters was also negligible.
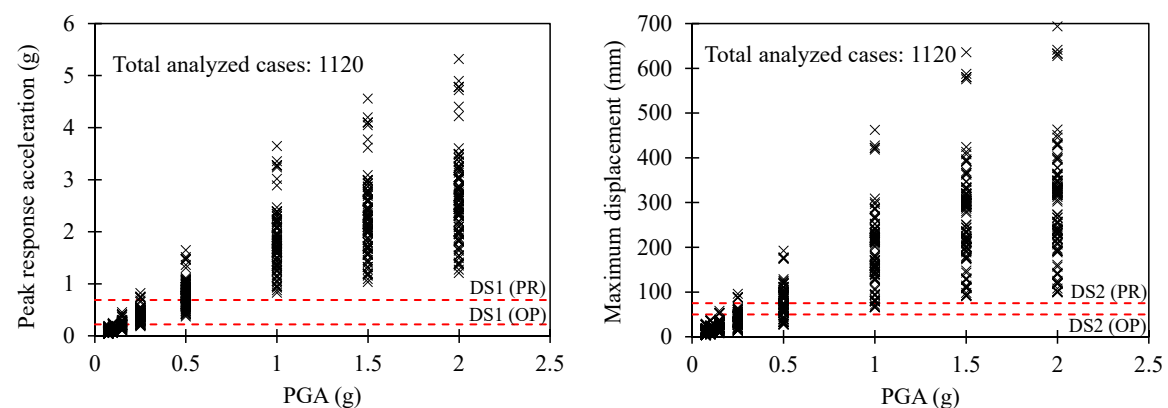

(a) Peak response acceleration at coils in Y-dir. (b) Maximum displacement at top beam beam in Y dir.

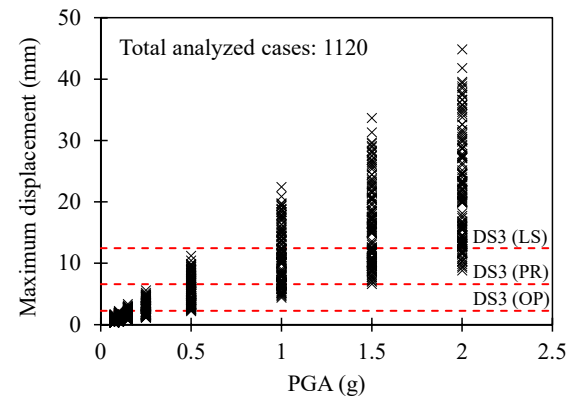

(c) Maximum displacement at bottom beam in $\mathrm{Z}$ dir

Figure 17. Variation of critical dynamic responses according to PGA obtained from analytical results.

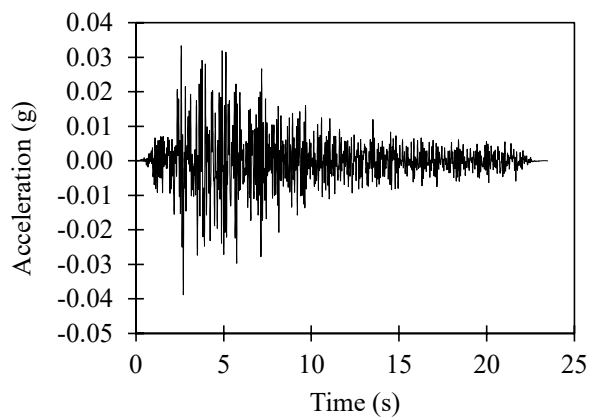

(a) Acceleration time history in Y-dir.

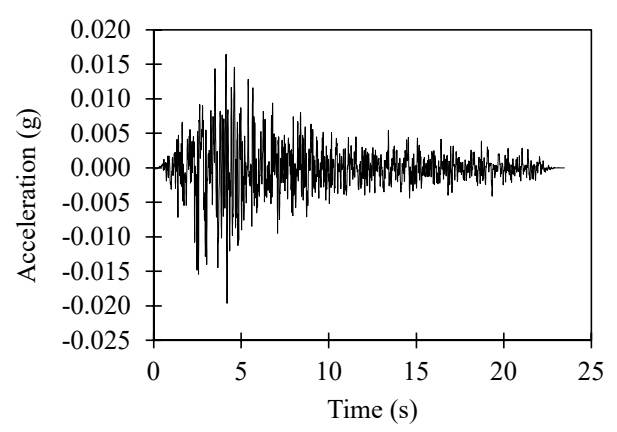

(c) Acceleration time history in Z-dir.

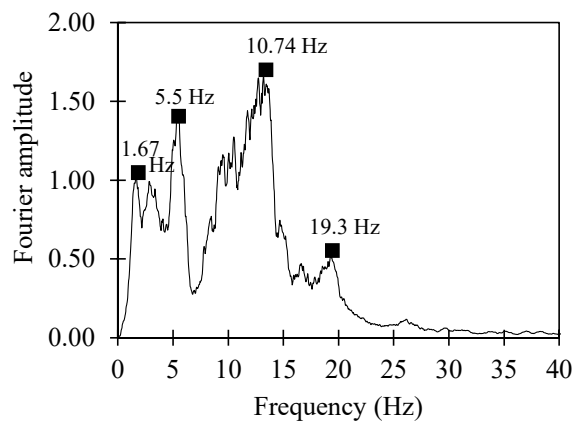

(b) FT result of acceleration time history in Y-dir.

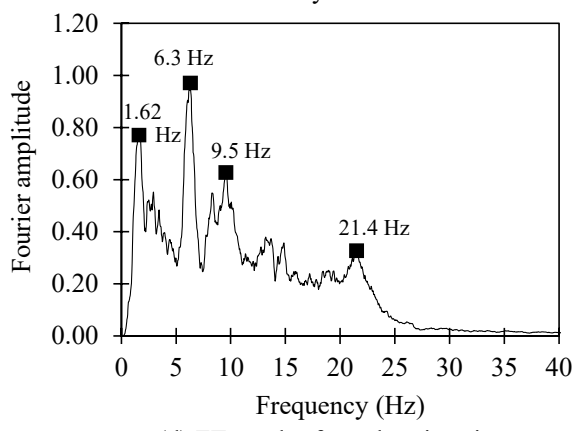

(d) FT result of acceleration time history in Z-dir.

Figure 18. Characteristics of Friuli_Italy-01 earthquake (Y and Z-directions). 


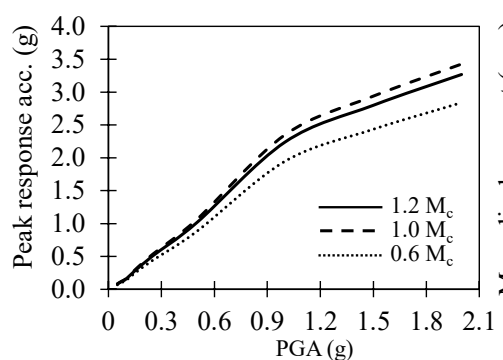

(a) Peak response acceleration at coil in Y-dir.

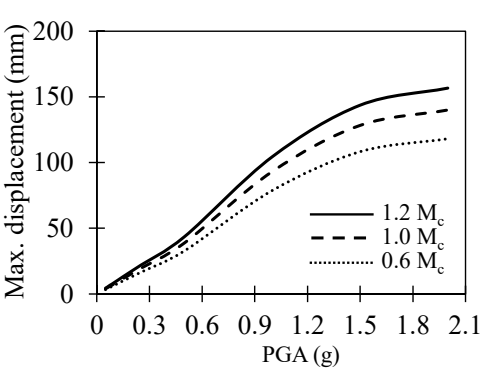

(b) Maximum displacement at top beam in Y-dir.

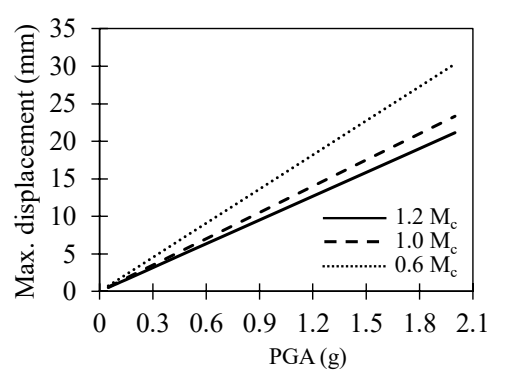

(c) Maximum displacement at bottom beam in Z-dir.

Figure 19. Effect of coil mass variation on dynamic responses according to PGA.

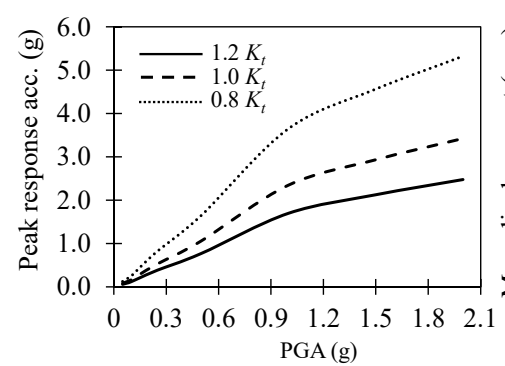

(a) Peak response acceleration at coil in Y-dir.

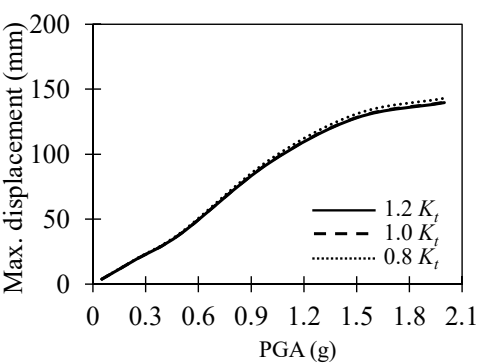

(b) Maximum displacement at top beam in Y-dir.

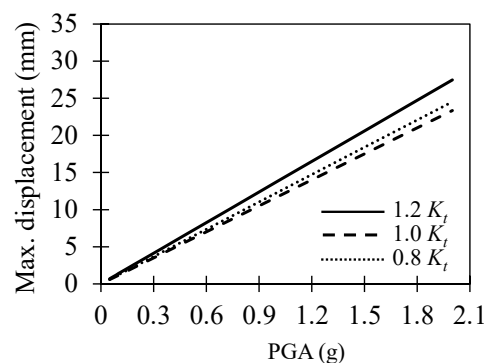

(c) Maximum displacement at bottom beam in Z-dir.

Figure 20. Effect of variation of effective translational stiffness on dynamic responses according to PGA.

Figures 21-23 present the effects of uncertainty in the modeling parameters on the fragility curves for the coil mass, effective translational stiffness, and rotational stiffness of the mold transformer. As shown in Figure 21, the variability of coil mass ultimately has little effect on the fragility curves corresponding to DS1; meanwhile, the fragility curves corresponding to DS2 and DS3 become flatter as the mass coil decreases. This is mainly attributed to the fact that the decrease of the mass coil leads to an increase in the natural time period, which leads to the decrease of deformation and finally the probability of exceeding limit states. Figure 22 shows that the variation of translational stiffness in the range of 0.8 to $1.2 K_{t}$ has almost no effect on the fragility curves corresponding to DS1 and DS2, but does have a significant effect on DS3. The increased translational stiffness significantly reduced the deformation in the Z-direction with the increase of PGA, leading to the decreased probability of exceeding limit states and the fragility curves becoming flatter. Similarly, Figure 23 indicates that the rotational stiffness has no effect on response acceleration and deformation in the Y-direction, leading to no change in the fragility curves corresponding to DS1 and DS2. Nonetheless, the change in rotational stiffness leads to slight variation of vertical deformation of the mold transformer, triggering the variation in the fragility curve with respect to DS3; however, this variation is not significant overall.

In order to estimate the complete fragility curves of the mold transformers, all analytical cases were combined to consider both variability in PGA and uncertain modeling parameters. Accordingly, the values of the median $(\theta)$ and the standard deviation $(\beta)$ were evaluated to establish fragility curves for different performance levels corresponding to damage states, and these are summarized in Table 7. By using Equations (6) and (7), the fragility curves of the mold transformer were derived for various damage states according to different performance levels, and these were presented in Figure 24. In Figure 24, the data points represented the fraction of exceedance of limit states for specific performance levels calculated from dynamic analyses. In addition, Figure 25 illustrates the differences in the probability of exceedance between analytical data and the fitted model according to PGA of different damage states. 
The critical PGA values corresponding to a specific probability of exceedance, which may play an important role in the seismic vulnerable evaluation; seismic design purposes were also determined from the fragility curves. Previous studies by Kildashti et al. [44], Parool et al. [45], and Talaat et al. [46] considered $50 \%$ probability of exceedance as the acceptance criteria. In this study, in order to consider the safety and the abundance of electrical transformer components in buildings, the value of $40 \%$ probability of exceedance was proposed as the acceptance criteria. Figure 24 also presents the critical PGA values corresponding to $40 \%$ probability of exceedance of the mold transformer. In detail, for the DS1 (Figure 24a), the $40 \%$ probability of exceedance corresponding to the OP and PR performance levels were predicted at PGA levels of $0.15 \mathrm{~g}$ and $0.4 \mathrm{~g}$, respectively. For the DS2 (Figure 24b), the $40 \%$ probability of exceedance corresponding to the OP and PR performance levels were predicted at PGA levels of $0.3 \mathrm{~g}$ and $0.45 \mathrm{~g}$, respectively. For the DS3 (Figure 24c), the $40 \%$ probability of exceedance corresponding to the OP, PR, and LS performance levels were predicted at PGA levels of $0.2 \mathrm{~g}, 0.6 \mathrm{~g}$, and $1.2 \mathrm{~g}$, respectively. For another value of the probability of exceedance, the critical PGA for each performance level corresponding to specific damage states could also be determined by using the fragility curves derived from the values of the median and the standard deviation presented in Table 7 .

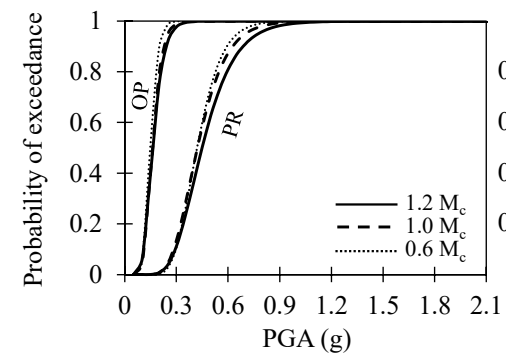

(a) Spacer damage (DS1)

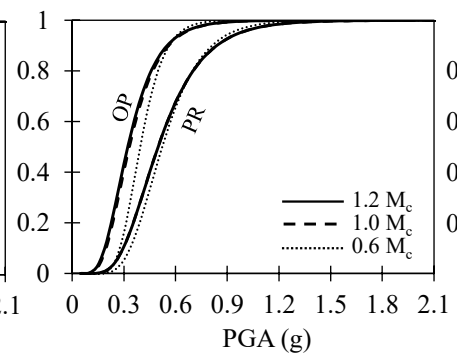

(b) Excessive movement in Y-dir. (DS2)

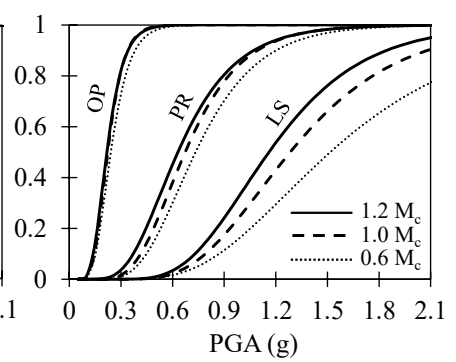

(c) Bottom bolt loosening (DS3)

Figure 21. Effect of coil mass variation on fragility curves of the mold transformer.

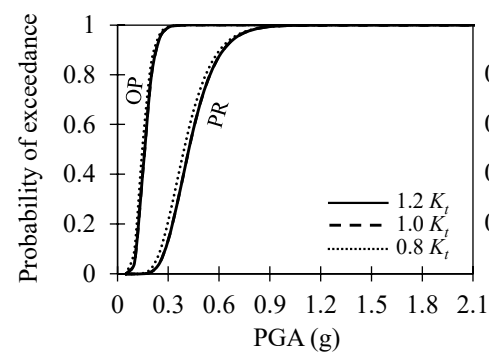

(a) Spacer damage (DS1)

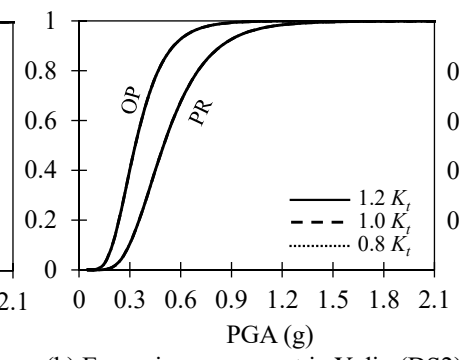

(b) Excessive movement in Y-dir. (DS2)

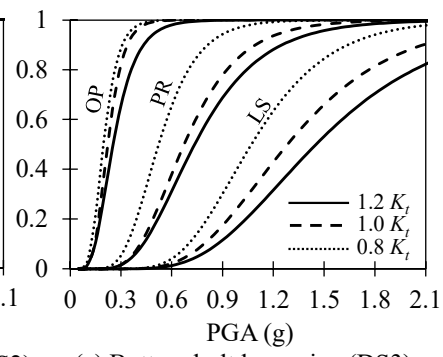

(c) Bottom bolt loosening (DS3)

Figure 22. Effect of variation of effective translational stiffness on fragility curves of the mold transformer.

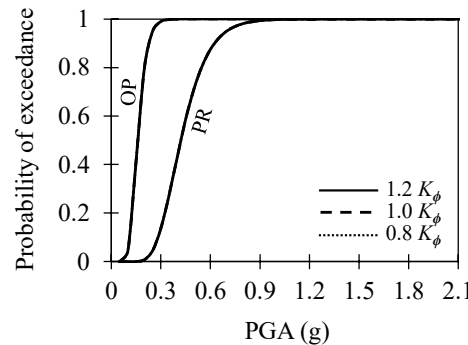

(a) Spacer damage (DS1)

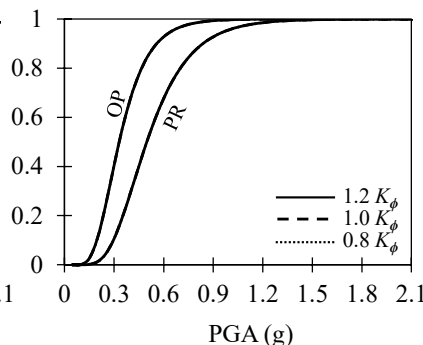

(b) Excessive movement in Y-dir. (DS2)

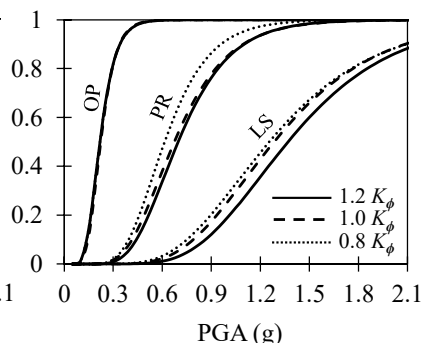

(c) Bottom bolt loosening (DS3)

Figure 23. Effect of variation of effective rotational stiffness on fragility curves of the mold transformer. 


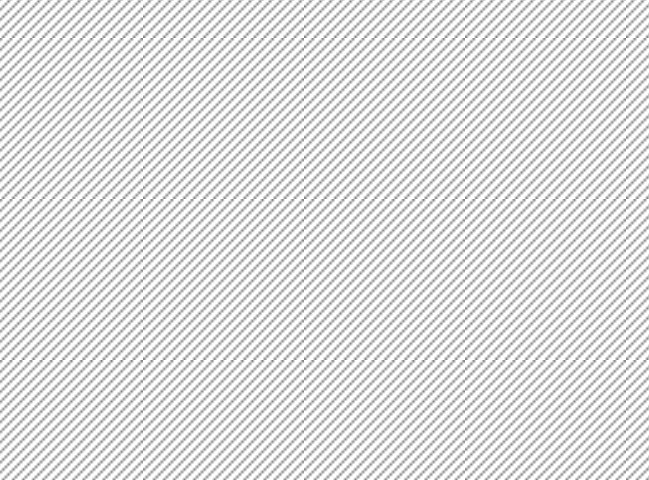

(a) Spacer damage (DS1)

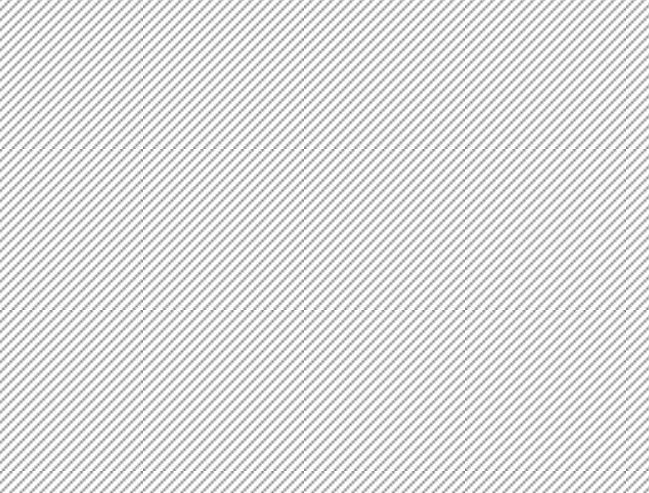

(c) Bottom bolt loosening (DS3)

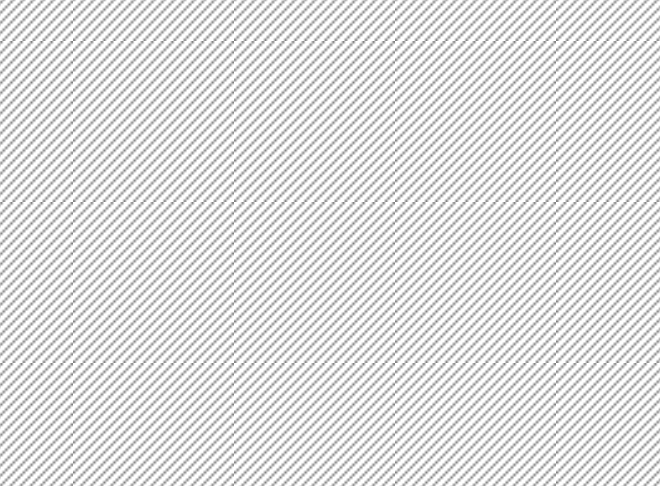

(b) Excessive movement in Y-dir. (DS2)

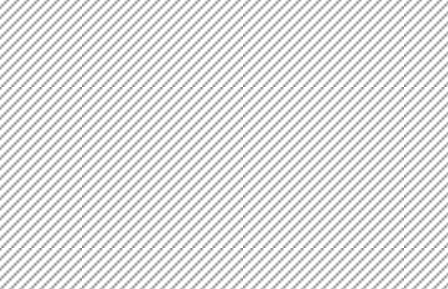

O Data point (Operational)

$\square$ Data point (Position retention)

- Data point (Life safety)

Fitting curve (Life safety)

Figure 24. Fragility curves for different damage states of the mold transformer.

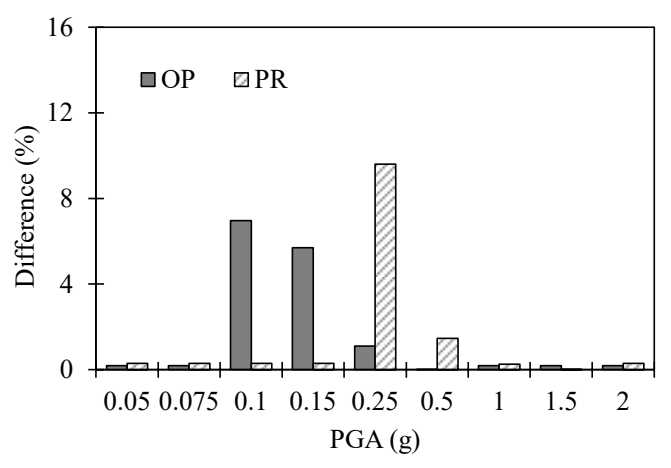

(a) Spacer damage (DS1)

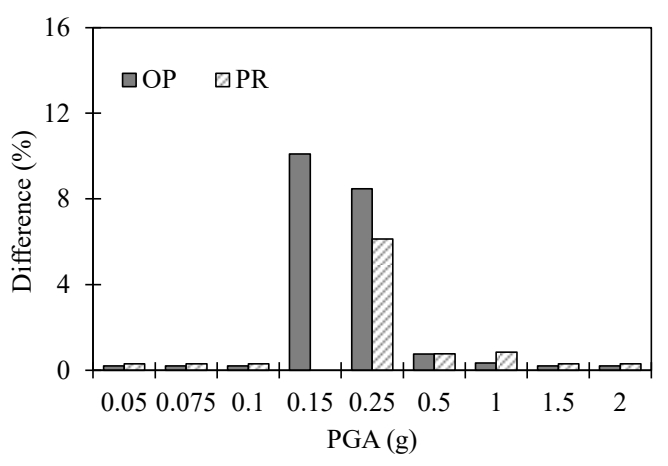

(b) Excessive movement in Y-dir. (DS2)

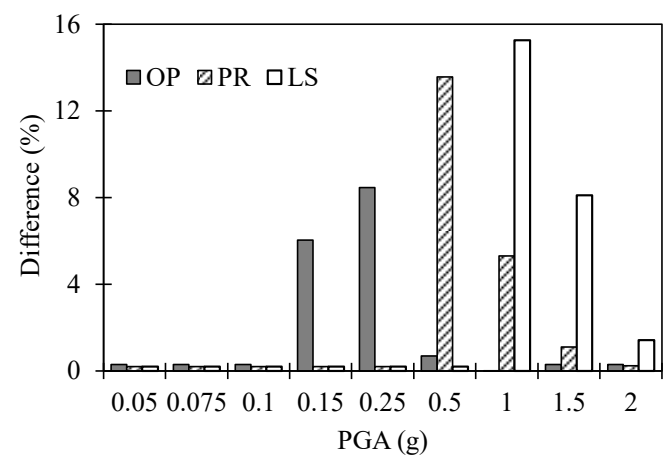

(c) Bottom bolt loosening (DS3)

Figure 25. Differences in the probability of exceedance between analytical data and the fitted model of different damage states. 
Table 7. Values of limit states of the mold transformer.

\begin{tabular}{cccc}
\hline Damage States & Performance Levels & Median $\boldsymbol{\theta}$ & Standard Deviation $\boldsymbol{\beta}$ \\
\hline \multirow{2}{*}{ DS1 } & OP & 0.16 & 0.28 \\
& PR & 0.42 & 0.31 \\
DS2 & OP & 0.34 & 0.40 \\
& PR & 0.50 & 0.40 \\
\multirow{2}{*}{ DS3 } & OP & 0.22 & 0.37 \\
& PR & 0.66 & 0.40 \\
& LS & 1.29 & 0.40 \\
\hline
\end{tabular}

\section{Conclusions}

In the present study, the seismic vulnerability of the mold transformer, which plays a crucial role in buildings, was assessed by dynamic analyses incorporating experimental results. In total, 1120 dynamic analysis cases were analyzed to describe the major characteristics of a prototype mold transformer. The truncated incremental dynamic analysis (TIDA) approach was used to estimate the seismic fragility curves with a set of 20 natural ground motions and three cases of uncertain modeling parameters including the effective translational stiffness, effective rotational stiffness, and the coil mass. The primary conclusions that may be drawn from this study are as follows:

1. The proposed analytical model showed good agreement with the data obtained from the shaking table test in terms of the shapes of acceleration-time history response, peak amplitude of acceleration response in tri-axial directions, the results of Fourier-transform (FT) analyses of acceleration response in frequency domain, the shapes of displacement-time history response, and the maximum displacement with a wide range of PGA.

2. Based on the shaking table test series results, three potential damage states were adopted to evaluate the seismic vulnerability: the failure of the spacers (DS1), the excessive movement in Y-direction (DS2), and the loosening of the linked bolts between the bottom beam and bed beam (DS3). Simultaneously, the limit values corresponding to the damage state for each performance level were also determined partly based on the test results and partly based on judgment.

3. The fragility curves were developed using the TIDA approach based on the analytical results, acceptance criteria from the test results, and the maximum likelihood estimator method, and they provided an overview of the failure probability of the hybrid mold transformers according to different PGAs and performance levels. Accordingly, for a given value of the probability of exceedance, the critical PGA for each performance level corresponding to specific damage states can be definitively determined.

4. The critical PGA values corresponding to $40 \%$ probability of exceedance, which may play an important role in the seismic vulnerable evaluation and seismic design purposes, were also determined from the fragility curves. The values for the cases of DS1 corresponding to the OP and PR performance levels were $0.15 \mathrm{~g}$ and $0.4 \mathrm{~g}$, respectively; the values for the cases of DS2 corresponding to the OP and PR performance levels were $0.3 \mathrm{~g}$ and $0.45 \mathrm{~g}$, respectively; and the values for the cases of DS2 corresponding to the OP, PR, and LS performance levels were $0.2 \mathrm{~g}$, $0.6 \mathrm{~g}$, and $1.2 \mathrm{~g}$, respectively.

Author Contributions: Methodology, N.H.D.; Investigation, J.-Y.K. and S.-J.L.; Writing-Original Draft Preparation, N.H.D.; Writing-Review \& Editing, K.-K.C.; Supervision, K.-K.C.

Funding: This research was supported by a grant (No. 19AUDP-C146352-02) from the Architecture \& Urban Development Research Program funded by the Ministry of Land, Infrastructure and Transport of the Korean Government.

Acknowledgments: We gratefully acknowledge the supports of Ministry of Land, Infrastructure and Transport of the Korean Government under a grand No. 19AUDP-C146352-02 from the Architecture \& Urban Development Research Program, and Soongsil University for supporting us.

Conflicts of Interest: The authors declare no conflicts of interest. 


\section{References}

1. Schiff, A.J. Northridge Earthquake: Lifeline Performance and Post-Earthquake Response; American Society of Civil Engineers: Reston, VA, USA, 1995.

2. Schiff, A.J. Guide to Improved Earthquake Performance of Electric Power Systems; US Department of Commerce, National Institute of Standards and Technology: Gaithersburg, MD, USA, 1998.

3. Qiang, X. Workshop on Electric System Earthquake Engineering; State Key Lab of Disaster Reduction in Civil Engineering, Tongji University: Shanghai, China, 2013.

4. Shinozuka, M.; Feng, M.; Dong, X.; Chang, S.E.; Cheng, T.C.; Jin, X.; Saadeghvaziri, M.A. Advances in Seismic Performance Evaluation of Power Systems; Res. Prog. Accompl. 2001-2003, Technical Report MCEER-03-SP01; Multidisciplinary Center for Earthquake Engineering Research: Buffalo, NY, USA, 2003.

5. Ersoy, S.; Feizi, S.; Ashrafi, A.; Ala Saadeghvaziri, M. Seismic Evaluation and Rehabilitation of Critical Components of Electrical Power Systems; Technical Report MCEER-08-0011; Multidisciplinary Center for Earthquake Engineering Research: Buffalo, NY, USA, 2008.

6. Korea Architectural Institute. Pohang Earthquake Damage Survey Report; Korea Architectural Institute: Seoul, Korea, 2018.

7. Whittaker, A.S.; Fenves, G.L.; Gilani, A.S. Seismic evaluation and analysis of high-voltage substation disconnect switches. Eng. Struct. 2007, 29, 3538-3549. [CrossRef]

8. Oikonomou, K.; Constantinou, M.C.; Reinhorn, A.M.; Yenidogan, C. Seismic isolation of electrical equipment "Seismic Table Simulation". In Proceedings of the 15th World Conference of Earthquake Engineering, Lisbon, Portugal, 24-28 September 2012.

9. Wen, B.; Taciroglu, E.; Niu, D. Shake table testing and numerical analysis of transformer substations including main plant and electrical equipment interaction. Adv. Struct. Eng. 2015, 18, 1959-1980. [CrossRef]

10. Ullah, N.; Ali, S.M.; Shahzad, R.; Khan, F. Seismic qualification and time history shake-table testing of high voltage surge arrester under seismic qualification level moderate. Cogent Eng. 2018, 5, 1431375. [CrossRef]

11. Wang, S.J.; Yang, Y.H.; Lin, F.R.; Jeng, J.W.; Hwang, J.S. Experimental study on seismic performance of mechanical/electrical equipment with vibration isolation systems. J. Earthq. Eng. 2017, 21, 439-460. [CrossRef]

12. Ye, J.; Jiang, L. Simplified Analytical Model and Shaking Table Test Validation for Seismic Analysis of Mid-Rise Cold-Formed Steel Composite Shear Wall Building. Sustainability 2018, 10, 3188. [CrossRef]

13. Lim, H.K.; Kang, J.; Pak, H.; Chi, H.S.; Lee, Y.G.; Kim, J. Seismic response of a three-dimensional asymmetric multi-storey reinforced concrete structure. Appl. Sci. 2018, 8, 479. [CrossRef]

14. Xu, W.; Yang, W.; Zhang, C.; Yu, D. Shake table test for the collapse investigation of a typical multi-story reinforced concrete frame structure in the meizoseismal area. Appl. Sci. 2017, 7, 593. [CrossRef]

15. Bahmani, P.; van de Lindt, J.; Iqbal, A.; Rammer, D. Mass timber rocking panel retrofit of a four-story soft-story building with full-scale shake table validation. Buildings 2017, 7, 48. [CrossRef]

16. Zareei, S.A.; Hosseini, M.; Ghafory-Ashtiany, M. Seismic failure probability of a $400 \mathrm{kV}$ power transformer using analytical fragility curves. Eng. Fail. Anal. 2016, 70, 273-289. [CrossRef]

17. Hur, J. Seismic Performance Evaluation of Switchboard Cabinets Using Nonlinear Numerical Models. Doctoral Dissertation, Georgia Institute of Technology, Atlanta, Georgia, 2012.

18. Wang, C.; Feng, K.; Zhang, H.; Li, Q. Seismic performance assessment of electric power systems subjected to spatially correlated earthquake excitations. Struct. Infrastruct. Eng. 2019, 15, 351-361. [CrossRef]

19. Vela, R.M.; Brunesi, E.; Nascimbene, R. Seismic assessment of an industrial frame-tank system: Development of fragility functions. Bull. Earthq. Eng. 2019, 17, 2569-2602. [CrossRef]

20. AISC. Specification for Structural Steel Buildings; American Institute of Steel Construction (AISC): Chicago, IL, USA, 2010.

21. AISC. Seismic Provisions for Structural Steel Buildings; American Institute of Steel Construction (AISC): Chicago, IL, USA, 2010.

22. OpenSees. Open System for Earthquake Engineering Simulation; Pacific Earthquake Engineering Research Center, University of California: Berkeley, CA, USA, 2006.

23. Nip, K.H.; Gardner, L.; Elghazouli, A.Y. Cyclic testing and numerical modelling of carbon steel and stainless steel tubular bracing members. Eng. Struct. 2010, 32, 424-441. [CrossRef]

24. International Conference of Building Officials (ICBO). ICBO AC 156 Acceptance Criteria for the Seismic Qualification of Nonstructural Components; ICBO Evaluation Service, Inc.: Whittier, CA, USA, 2000. 
25. MIDAS. Integrated Solution System for Building and General Structures; MIDAS Information Technology Co., Ltd.: Gyeonggi-do, Korea, 2018.

26. Chopra, A.K. Dynamics of Structures: Theory and Applications to Earthquake Engineering, 5th ed.; Prentice Hall: Englewood Cliff, NJ, USA, 2016.

27. Dinh, N.H.; Lee, S.J.; Kim, J.Y.; Choi, K.K. Seismic performance of the mold transformer through shaking table tests. J. Earthq. Eng. 2019, in press.

28. Baker, J.W. Efficient analytical fragility function fitting using dynamic structural analysis. Earthq. Spectra 2015, 31, 579-599. [CrossRef]

29. Zentner, I.; Gündel, M.; Bonfils, N. Fragility analysis methods: Review of existing approaches and application. Nucl. Eng. Des. 2017, 323, 245-258. [CrossRef]

30. Cornell, C.A.; Jalayer, F.; Hamburger, R.O.; Foutch, D.A. Probabilistic basis for 2000 SAC federal emergency management agency steel moment frame guidelines. J. Struct. Eng. 2002, 128, 526-533. [CrossRef]

31. Ghafory-Ashtiany, M.; Mousavi, M.; Azarbakht, A. Strong ground motion record selection for the reliable prediction of the mean seismic collapse capacity of a structure group. Earthq. Eng. Struct. Dyn. 2011, 40, 691-708. [CrossRef]

32. Federal Emergency Management Agency (FEMA). Multi-Hazard Loss Estimation Methodology, Hazus Technical and User's Manuals; Federal Emergency Management Agency: Washington, DC, USA, 2010.

33. Rossetto, T.; Elnashai, A. A new analytical procedure for the derivation of displacement-based vulnerability curves for populations of RC structures. Eng. Struct. 2005, 27, 397-409. [CrossRef]

34. Shinozuka, M.; Feng, M.Q.; Lee, J.; Naganuma, T. Statistical analysis of fragility curves. J. Eng. Mech. 2000, 126, 1224-1231. [CrossRef]

35. Vamvatsikos, D.; Cornell, C.A. Incremental dynamic analysis. Earthq. Eng. Struct. Dyn. 2002, 31, $491-514$. [CrossRef]

36. ATC-58. Guidelines for Seismic Performance Assessment of Buildings; Applied Technology Council: Redwood City, CA, USA, 2007.

37. PEER. PEER NGA, Database; Pacific Earthquake Engineering Research Center, University of California: Berkeley, CA, USA, 2006.

38. Architectural Institute of Korea. Korean Building Code and Commentary; Architectural Institute of Korea: Seoul, Korea, 2016.

39. Lanzano, G.; Salzano, E.; De Magistris, F.S.; Fabbrocino, G. Seismic vulnerability of gas and liquid buried pipelines. J. Loss Prev. Process. Ind. 2014, 28, 72-78. [CrossRef]

40. Phan, H.N.; Paolacci, F. Efficient intensity measures for probabilistic seismic response analysis of anchored above-ground liquid steel storage tanks. In Proceedings of the ASME 2016 Pressure Vessels and Piping Conference, Vancouver, BC, Canada, 17-21 July 2016.

41. Porter, K. Beginner's guide to fragility, vulnerability, and risk. Encycl. Earthq. Eng. 2015, 235-260. [CrossRef]

42. American Society of Civil Engineers. Seismic Evaluation and Retrofit of Existing Buildings; American Society of Civil Engineers: Reston, VA, USA, 2017.

43. Korea Radio Research Institute. Earthquake Resistance Test Method for Telecommunication Facilities; Korea Radio Research Institute: Jeollanam-do, Korea, 2015.

44. Kildashti, K.; Mirzadeh, N.; Samali, B. Seismic vulnerability assessment of a case study anchored liquid storage tank by considering fixed and flexible base restraints. Thin Walled Struct. 2018, 123, 382-394. [CrossRef]

45. Parool, N.; Rai, D.C. Seismic fragility of multispan simply supported bridge with drop spans and steel bearings. J. Bridge Eng. 2015, 20, 04015021. [CrossRef]

46. Talaat, M.M.; Hamburger, R.O. Reliability of Acceptance Criteria in Nonlinear Response History Analysis of Tall Buildings. In Proceedings of the 15th World Conference on Earthquake Engineering 2012 (15WCEE), Lisbon, Portugal, 24-28 September 2012.

(C) 2019 by the authors. Licensee MDPI, Basel, Switzerland. This article is an open access article distributed under the terms and conditions of the Creative Commons Attribution (CC BY) license (http://creativecommons.org/licenses/by/4.0/). 